\title{
Anti-VEGF-Resistant Retinal Diseases: A Review of the Latest Treatment Options
}

\author{
Josh O. Wallsh ${ }^{1}$ and Ron P. Gallemore ${ }^{2, *}$ \\ 1 Department of Ophthalmology, Albany Medical College, Albany, NY 12208, USA; jwallsh@hotmail.com \\ 2 Retina Macula Institute, Torrance, CA 90503, USA \\ * Correspondence: rongallemoremd@gmail.com
}

Citation: Wallsh, J.O.; Gallemore, R.P. Anti-VEGF-Resistant Retinal

Diseases: A Review of the Latest Treatment Options. Cells 2021, 10, 1049. https://doi.org/10.3390/ cells10051049

Academic Editors: Reinier

O. Schlingemann and Alexander

E. Kalyuzhny

Received: 3 April 2021

Accepted: 28 April 2021

Published: 29 April 2021

Publisher's Note: MDPI stays neutral with regard to jurisdictional claims in published maps and institutional affiliations.

Copyright: (C) 2021 by the authors. Licensee MDPI, Basel, Switzerland. This article is an open access article distributed under the terms and conditions of the Creative Commons Attribution (CC BY) license (https:/ / creativecommons.org/licenses/by/ $4.0 /)$.

\begin{abstract}
Anti-vascular endothelial growth factor (anti-VEGF) therapy currently plays a central role in the treatment of numerous retinal diseases, most notably exudative age-related macular degeneration (eAMD), diabetic retinopathy and retinal vein occlusions. While offering significant functional and anatomic benefits in most patients, there exists a subset of $15-40 \%$ of eyes that fail to respond or only partially respond. For these cases, various treatment options have been explored with a range of outcomes. These options include steroid injections, laser treatment (both thermal therapy for retinal vascular diseases and photodynamic therapy for eAMD), abbreviated anti-VEGF treatment intervals, switching anti-VEGF agents and topical medications. In this article, we review the effectiveness of these treatment options along with a discussion of the current research into future directions for anti-VEGF-resistant eyes.
\end{abstract}

Keywords: anti-VEGF; macular degeneration; diabetic retinopathy; resistant; retinal vein occlusion

\section{Introduction}

Vascular endothelial growth factor (VEGF) is now known to play a central role in the vascular changes associated with the leading causes of blindness in developed countries, namely age-related macular degeneration (AMD), diabetic retinopathy and retinal vein occlusions (RVOs) [1-3]. Each of these disorders is associated with vascular leakage and proliferation which can lead to retinal edema, hemorrhaging and vision loss. The advent of anti-VEGF therapy for cancer, specifically bevacizumab (IVB; Avastin; Genentech; South San Francisco, CA, USA), led to the use of the same drug in exudative AMD (eAMD) and was found to be highly effective. In clinical trials, this agent and the more recently developed drugs ranibizumab (IVR; Lucentis; Genentech; South San Francisco, CA, USA), aflibercept (IVA; Eylea; Regeneron; Tarrytown, NY, USA) and brolucizumab (IVBr, Beovu; Novartis; Basel, Switzerland) have been shown to be able to reduce vascular leakage and proliferation and, in anywhere from 50-95\% of eyes, improve vision [4-8]. There are, however, a small percentage of patients $-20-40 \%$ in eAMD [4] and $15-20 \%$ in diabetic retinopathy $[9,10]$ - who do not adequately or fully respond to anti-VEGF therapy and require alternate treatment strategies for their management. Alternatives include steroids, topical medications, laser treatments (thermal and photodynamic therapy) and, more recently, a host of other potential agents to effect improvement. Herein, we review the biological bases for failure to respond and the current and imminent therapies that may be utilized. While an exhaustive search of all the previously investigated therapeutic options was not performed, the following is a presentation of the selected literature illustrative of the available approaches.

\section{Background}

For most causes of vascular leakage, anti-VEGF therapy alone is sufficient to reduce leakage and restore vision. In the case of eAMD, randomized clinical trials of treatment naïve eyes found that treatments are effective at reducing leakage and improving vision in 
$59-68 \%$ of cases for IVB [11,12], 61-75\% for IVR [6,12] and 79-83\% for IVA [4,6]. It is the $20-40 \%$ of patients that may not respond and an additional subset of partial responders who require alternative treatment approaches for maximal therapeutic effect. Given the ambiguity in these terms, Amoaku et al. attempted to define non-responders and partial responders in eAMD based upon visual and anatomic responses. [13] Non-responders were defined as visual acuity decline of greater than 5 letters and/or optical coherence tomography (OCT) findings of unchanged or increased macular thickness and pigment epithelium detachment (PED). Partial responders have a visual acuity improvement of 1-5 letters from baseline and/or the following OCT findings: $25-75 \%$ decrease in macular thickness, persistence of subretinal or intraretinal fluid and/or new subretinal or intraretinal fluid. An additional group, poor responders, was also defined as visual acuity decrease of 0-4 letters from baseline and/or $<25 \%$ decrease in macular thickness on OCT. In the case of diabetic retinopathy and RVOs, there has been less consistency regarding the definition of anti-VEGF resistance. For diabetic retinopathy-specifically diabetic macular edema (DME) - anti-VEGF resistance has been mainly defined based on OCT images either utilizing the percent decrease in macular thickness compared to pre-treatment $(<25 \%)[14,15]$ or a threshold based on the macular thickness after a series of anti-VEGF injections (ranging from $\geq 225-300 \mu \mathrm{m}$ ) [15-18]. On the other hand, the definition of anti-VEGF resistance in eyes with RVOs has been based both on OCT (persistent edema or fluid) and/or visual acuity (no improvement) parameters [19-21]. For the purposes of the following review of treatment options, partial, poor and non-responders have all been termed anti-VEGFresistant cases. The development of anti-VEGF resistance can occur following any number of injections, but it is important to evaluate all the relevant data prior to classifying a patient as "anti-VEGF resistant." While the recurrence or persistence of intraretinal or subretinal fluid on OCT is important, if the visual acuity is maintaining or improving then the eye may not truly be anti-VEGF resistant.

While the focus has been on VEGF-mediated leakage and vascular proliferation as the causes of vision loss in eAMD, diabetic retinopathy and RVOs, it is clear that there are other players involved. The literature is confusing, however, with some review articles talking about VEGF as being the corner stone or rate limiting factor causing pathologic vascular leakage and proliferation. Other reviews describe separate pathways where cytokines, for example, directly mediate leakage independent of VEGF (Figure 1) [22-25]. There is literature supporting both views-for example, the cytokine prostaglandin E2 can directly cause vascular leakage and proliferation but can also upregulate VEGF [26-29]. Both pathways likely play some role in the development of leakage.

Patients with anti-VEGF-resistant leakage have a different biological picture than the average person. Given the origins of anti-VEGF therapy are in oncology, resistance in cancers may provide insight into the culprits of anti-VEGF resistance in retinal diseases. These studies have demonstrated the importance of alternative proangiogenic factors in the development of anti-VEGF resistance such as platelet-derived growth factor, fibroblast growth factor, placental growth factor, interleukins and transforming growth factor- $\beta[30,31]$. Many of these factors have also been implicated in the development of retinal diseases and may be upregulated in light of VEGF blockade [32-35]. As such, there have been investigators promoting the sampling of factors in the vitreous fluid to develop customized approaches for the treatment of retinal diseases [36]. Until such therapeutic options are available, the following treatment approaches are capable of treating such anti-VEGF-resistant cases. 


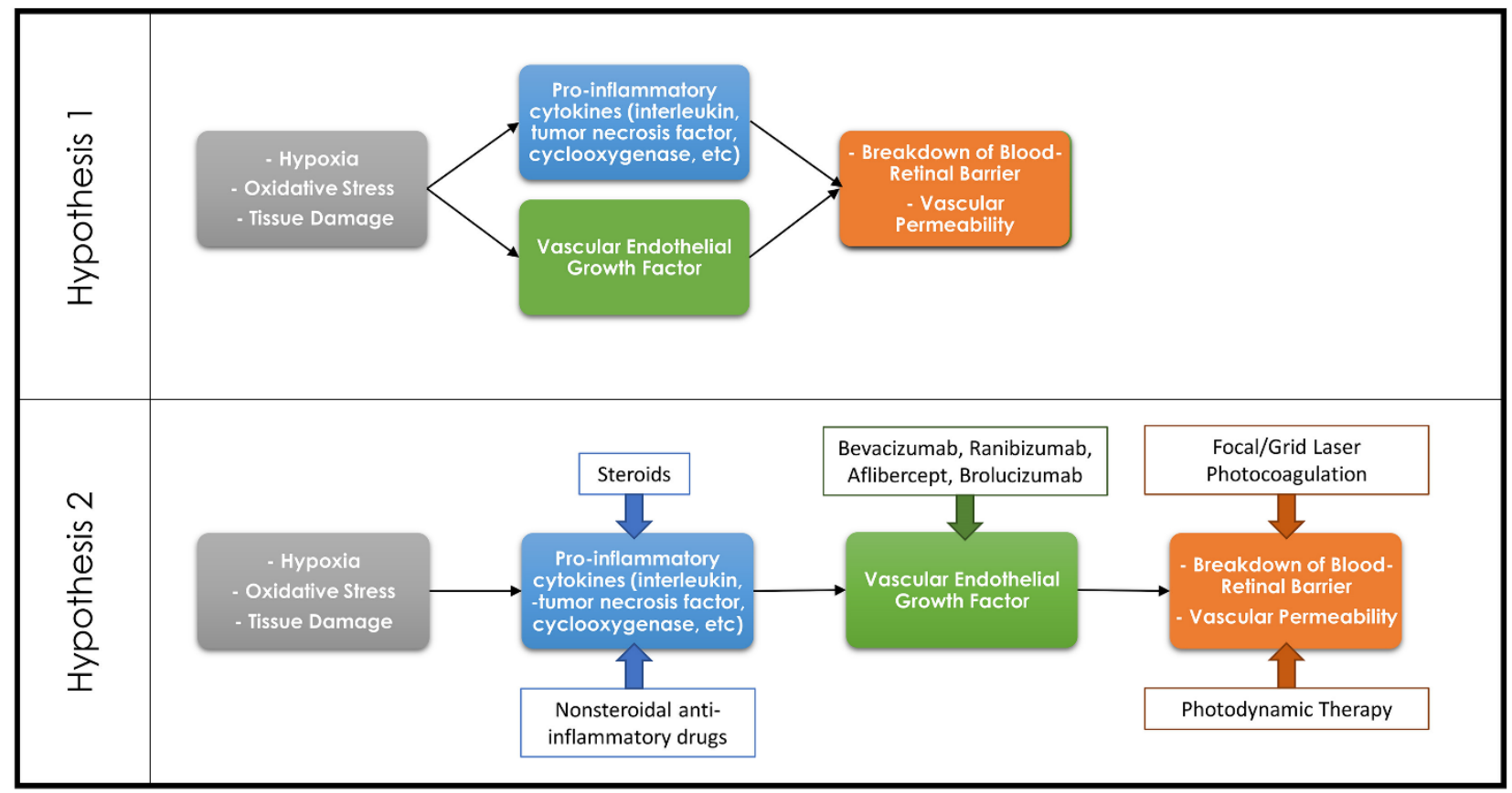

Figure 1. Diagram demonstrating the countering theories regarding the association of the inflammatory cascade and VEGF in the development of retinal pathologies. Hypothesis 1 theorizes that the inflammatory cascade and VEGF are both separate pathways resulting in a breakdown of the blood-retinal barrier, whereas Hypothesis 2 theorizes that the inflammatory cascade results in upregulation of VEGF which in turn leads to the breakdown of the blood-retinal barrier. Common therapeutic options and their targets within these pathways are demonstrated on the Hypothesis 2 diagram.

\section{Exudative Age-Related Macular Degeneration}

\subsection{Alternative Anti-VEGF Dosing Strategies}

The current anti-VEGF treatment strategy involves a loading dose series of three monthly injections followed by a transition to a pro re nata (PRN) or treat-and-extend strategy depending on physician preference. With all of these treatments, the shortest interval between injections is four weeks $[37,38]$. Several studies have evaluated shorter treatment intervals in anti-VEGF-resistant eAMD. Mimouni et al. retrospectively evaluated 27 eyes with anti-VEGF-resistant eAMD that received IVB every two weeks for a series of three to four injections. Overall, no significant change was appreciated in visual acuity or macular thickness, but a subset of 6 eyes $(22.2 \%)$ were noted to have complete resolution of subretinal fluid on OCT [39]. Similarly, Witkin et al. retrospectively evaluated 18 eyes with anti-VEGF-resistant eAMD treated with alternating IVB and IVR every two weeks for four doses. These eyes experienced significant improvements in visual acuity (20/95 to 20/65) and macular thickness (455 to $387 \mu \mathrm{m}$ ) [40]. Mathematical models have also suggested similar intraocular benefits with the two-week regimen associated with more sustained anti-VEGF activity compared to four-week dosing [41]. In the case of IVA, the recommended dosing is a loading dose series of three injections every month followed by injections every eight weeks. Multiple studies have noted significant improvements in macular thickness when IVA was injected at four-week intervals, rather than every eight weeks, in anti-VEGF-resistant eyes. Visual acuity results, however, did not show a change when transitioned to such therapy [42,43]. These studies demonstrate that a subset of patients with eAMD initially resistant to anti-VEGF therapy may respond to shorter treatment intervals.

Treating at shorter intervals has not been the only alternative dosing strategy attempted in anti-VEGF-resistant eAMD. Some researchers have also attempted larger doses at regular intervals. Routine dosing of IVR and IVA have been with $0.5 \mathrm{mg}$ and $2 \mathrm{mg}$, respectively. The HARBOR study demonstrated equivalent outcomes between 0.5 and $2 \mathrm{mg}$ IVR dosing in treatment naïve eAMD eyes [44]. Assessment of $2 \mathrm{mg}$ IVR in anti- 
VEGF-resistant eAMD eyes was performed in the SAVE trial. Following the initial threemonth loading dose, 87 eyes were noted to have significant improvements in visual acuity (3.3 letter increase) and macular thickness ( $33.1 \mu \mathrm{m}$ improvement) [45]. These results were noted to persist for one and two years while undergoing continued $2 \mathrm{mg}$ IVR dosing using a PRN regimen [46,47]. Fung et al. performed a randomized controlled trial comparing 0.5 and $2 \mathrm{mg}$ dosing in anti-VEGF-resistant eAMD eyes; however, these results were limited by a small sample size ( 7 eyes receiving $2 \mathrm{mg}$, 2 eyes receiving $0.5 \mathrm{mg}$ ). At the six-month follow-up, significant improvements were noted in visual acuity and macular thickness in the $2 \mathrm{mg}$ cohort only; although at one year these improvements diminished slightly and were no longer significant [48]. You et al. retrospectively evaluated $4 \mathrm{mg}$ IVA in anti-VEGF-resistant eyes and demonstrated a significant improvement in macular thickness but visual acuity was unchanged [49]. Although higher anti-VEGF doses did not appear to be beneficial to outcomes in treatment naïve eyes, there is evidence that some anti-VEGF-resistant eyes may improve in response to these dosing changes.

Important considerations when employing either shorter treatment intervals or higher anti-VEGF doses are the possible systemic side effects. There have been concerns raised about systemic exposure to anti-VEGF following intravitreal injections leading to increased rates of myocardial infarctions, cerebrovascular accidents or thromboembolic events [50,51]. Such systemic exposures would likely be increased with the alternative dosing regimens discussed above, but no increase in these complications were noted. In more recent years, real world research has questioned whether these systemic complications were more common with intravitreal anti-VEGF injections [52]. These systemic side effects should still be considered when employing these alternative dosing regimens especially in at risk groups.

\subsection{Tachyphylaxis and Switching Anti-VEGF Medications}

Many eyes with eAMD initially responsive to a single anti-VEGF agent will develop resistance or tachyphylaxis over repeated treatments. To counteract this resistance, numerous researchers have proposed switching agents to a different anti-VEGF which may offer improved responsiveness. Similarly, some eyes will be unresponsive to one anti-VEGF medication but when challenged with a different agent show a substantial response. In a study of 63 treatment naïve eyes with eAMD initiating anti-VEGF therapy, 14 eyes $(22.2 \%)$ were unresponsive to initial anti-VEGF medication and 8 eyes $(12.7 \%)$ developed tachyphylaxis in the one year of follow-up [53]. This rate of tachyphylaxis certainly increases as patients are treated for beyond one year.

The U.S. Food and Drug Administration (FDA) approval of IVA for the treatment of eAMD offered a novel anti-VEGF medication option after years of only having IVR and IVB available. This was especially important for the treatment of anti-VEGF unresponsive eyes and those with tachyphylaxis. Numerous investigators have evaluated its efficacy in these circumstances and all demonstrated some benefit [54-62]. Two meta-analyses attempted to evaluate the pooled data from these numerous studies. Seguin-Greenstein et al. noted that macular thickness improved significantly in all studies but reported only a nonsignificant improvement in visual acuity. Although, the analysis did reveal a significant improvement in visual acuity in the pooled prospective studies [63]. Similarly, Spooner et al. noted significant macular thickness improvements in all studies with nonsignificant visual acuity improvements. This analysis once again noted better visual acuity results in the pooled prospective studies but were only significant at the six-month follow-up [64]. Both of these studies only evaluated the response one year after switching medications to IVA, but a few other studies have investigated longer results. Jørstad et al. prospectively evaluated 50 eAMD eyes resistant to IVB and/or IVR transitioned to IVA. After one and two years, the macular thickness improved significantly; however, visual acuity results demonstrated less benefit. At the one-year follow-up visual acuity was unchanged from baseline and, in fact, decreased at the two-year follow-up (20/36 to 20/42). In addition, 5 eyes $(10 \%)$ were switched from IVA treatment prior to the completion of the two-years 
study period due to a poor response [60]. In a separate study, Spooner et al. evaluated 39 eAMD eyes with 48 months of follow-up after switching to IVA. Both visual acuity and macular thickness significantly improved after one year, but while macular thickness improvement persisted throughout, visual acuity returned to baseline by 48 months [54]. Another important consideration in the decision to transition to IVA is the presence of a vascularized PED which can be a treatment challenge in eyes with eAMD. Multiple studies have demonstrated significant benefits to the use of IVA over other anti-VEGF agents with flattening of the vascularized PED and improved visual acuity results [65-67]. Furthermore, multiple investigators have demonstrated a beneficial anatomic response in such eyes resistant to IVB or IVR associated with stable visual acuity outcomes [68-71]. Transitioning to IVA offers anatomic benefits and, in many eyes, those benefits will equate to visual improvement as well. Over time, however, these visual benefits appear to be transient which may hasten a switch to an alternative therapeutic option [72].

When eyes with eAMD develop tachyphylaxis or are unresponsive to IVA, some have theorized a switch back to IVR (or even IVB) may be beneficial. The SAFARI study prospectively evaluated switching to IVR for a series of three monthly doses followed by PRN dosing for the six-month trial. A total of 100 eyes were included and nonsignificant improvements in mean macular thickness $(-35.38 \mu \mathrm{m})$ and visual acuity $(+1.9$ letters) were noted at six months. In total, $34 \%$ of eyes were noted to have an increase of 5 or more letters after the switch in therapy [73]. Other smaller, retrospective studies have demonstrated similar benefits when switching to IVR in a subset of eyes with eAMD unresponsive to IVA $[74,75]$. In addition, the more recently FDA approved IVBr offers an additional therapeutic option for anti-VEGF-resistant eAMD that has developed tachyphylaxis to other agents. We reported in a case series of six anti-VEGF-resistant eyes the macular thickness benefit associated with a switch to IVBr, including eyes previously treated with IVA. These results did not demonstrate improved visual acuity outcomes [76].

The development of tachyphylaxis offers a treatment challenge, but numerous studies have demonstrated that switching anti-VEGF medication can be beneficial for many such eyes. Both IVA and IVBr appear to play a key role in the initial therapeutic approach when treating eyes that develop tachyphylaxis to other therapeutic agents. These agents have significantly different molecular structures and sizes when compared to the ranibizumab and bevacizumab compounds which may play a role when the retina becomes sensitized to these anti-VEGF treatments.

\subsection{Photodynamic Therapy}

Photodynamic therapy (PDT) as a treatment option for eAMD precedes the current anti-VEGF therapies but has fallen out of favor as a primary treatment. The therapy relies on an intravenous injection of verteporfin (Visudyne; Bausch + Lomb; Rochester, NY) which is then activated when in the retinal and choroidal circulation by a low-energy laser at $689 \mathrm{~nm}$ wavelength. Activation of verteporfin results in the creation of free radicals which cause vascular endothelial cell damage. When applied to the choroidal neovascular membrane in eAMD, it results in regression of the membrane but recurrence is common and repeat treatment is required. In eyes with anti-VEGF resistance, PDT may offer an alternative treatment option.

Multiple studies have evaluated various PDT protocols in the treatment of anti-VEGFresistant eAMD. Park et al. retrospectively evaluated 78 eyes with anti-VEGF-resistant eAMD treated with reduced fluence PDT (laser delivered for a shorter period of time resulting in a $20 \%$ reduction in energy density delivered from standard therapy) [77]. All enrolled eyes initially received PDT as "rescue therapy" based on a lack of resolution of subretinal and/or intraretinal fluid along with macular thickening despite a series of three anti-VEGF injections. Anti-VEGF injections were allowed to be initiated on a PRN basis three months after PDT treatment and repeat "rescue therapy" with PDT allowed if the same parameters previously discussed were met again. Three months after PDT, visual acuity improved significantly but subsequently decreased and was significantly worse 
than baseline from 24 through 60 months. In addition, exudation as determined by OCT had resolved in 55 eyes (77\%) after three months but at about a year had recurred in 49 of these eyes. During the follow-up, 34 patients (44\%) required repeat PDT "rescue therapy" with macular atrophy overall reported as the most common complication in 30 patients (39\%) which may explain the poorer visual outcomes. Two other studies investigated combination PDT and anti-VEGF treatment (double therapy) in eAMD eyes resistant to anti-VEGF monotherapy. Tozer et al. combined half-fluence PDT (defined as laser applied at $300 \mathrm{~mW}, 25 \mathrm{~J}, 83 \mathrm{~s}$ ) with IVB in 26 eyes. These eyes were followed for 6 months after combination therapy and anti-VEGF injections were continued on a PRN basis after combination therapy. Visual acuity improved significantly at three months and macular thickness significantly improved at all follow-ups [78]. Silva-Garcia et al. also treated antiVEGF-resistant eAMD eyes with double therapy and noted relative stability five years after treatment in 11 eyes with many others remaining inactive throughout that time period. An important note regarding the 29 eyes included in this study, the inclusion criteria required inactive choroidal neovascularization for one year following combination treatment so not all eyes treated at this practice were included [79]. Triple therapy (PDT, intravitreal anti-VEGF and intravitreal steroids) has not been studied specifically in this population of anti-VEGF-resistant patients, but may offer an additional benefit to these challenging cases providing treatment of multiple aspects associated with the pathophysiology of eAMD [80,81]. The PDT to regress the choroidal neovascular membrane and vascular permeability, anti-VEGF treatment to counteract the drive for neovascularization and the anti-inflammatory properties of the steroid. Overall, PDT offers an effective therapy with an extended course of action; however, recurrence commonly occurs after a year so repeat therapy or an alternative treatment modality is necessary. Additionally, the concern exists for possible retinal pigment epithelium tears and progression of atrophy, so this must be considered and discussed when recommending such intervention.

\subsection{Steroids}

Intravitreal steroids have been a mainstay of therapy for numerous retinal vascular disorders for many years but have overall not found favor in the treatment of eAMD. In the case of anti-VEGF-resistant eAMD, some have proposed that an inflammatory component is partially to blame for this resistance [82]. This has led to the application of intravitreal steroids in the treatment of anti-VEGF-resistant eAMD. Tao and Jonas evaluated combination intravitreal triamcinolone acetonide (IVTA; TRIESENCE; Alcon; Fort Worth, TX, USA) and IVB injections in 31 eyes with anti-VEGF-resistant eAMD [83]. These eyes were followed for seven months, receiving one combination treatment followed by two additional IVB injections every two months. Initially, visual acuity and macular thickness improved significantly at two and four months after combination therapy. At seven months, both visual acuity and macular thickness continued to be improved from baseline but no longer significantly. The intravitreal dexamethasone implant (DEX; Ozurdex; Allergan; Dublin, Ireland) offers an extended-release intraocular steroid therapy which has been evaluated by multiple investigators in combination therapy for anti-VEGF-resistant eAMD. Todorich et al. retrospectively evaluated 18 eyes over six months initially treated with a combination of intravitreal DEX and anti-VEGF followed by PRN anti-VEGF dosing. These eyes had a significant improvement in macular thickness but no significant change in visual acuity after six months [84]. Barikian et al. similarly evaluated 19 eyes with eAMD unresponsive to a series of IVB and IVR subsequently treated with a single combination treatment of intravitreal DEX and IVR followed by PRN IVR for six months. Again, a significant improvement in macular thickness was noted, but visual acuity remained unchanged [85]. Giancipoli et al. found similar anatomic benefit with intravitreal DEX in 11 eyes with eAMD resistant to anti-VEGF but without significant visual acuity improvement [86]. Intraocular pressure and cataract progression remain possible complications with such therapy and should be considered when initiating treatment with steroids. Although treatment with steroids may 
offer some benefit in anti-VEGF-resistant eAMD, the response has been short-lived and overall underwhelming.

\subsection{Miscellaneous Treatment Considerations}

In a number of smaller studies, alternative treatment approaches have been evaluated including the use of oral medications or surgical interventions (Table 1). Another important consideration is ensuring that the correct diagnosis is being treated when a patient is unresponsive or poorly responsive to anti-VEGF therapy. Specifically, in the case of eAMD, the possibility of polypoidal choroidal vasculopathy (PCV) should be considered.

Perceived to be a variant of eAMD, PCV is most commonly seen in Asian patients $[87,88]$ with characteristic indocyanine green angiography findings. [89] Treatment of PCV can be challenging and numerous studies have evaluated possible treatment approaches including the use of anti-VEGF and PDT monotherapy. [90-92] Despite benefits to both therapeutic options alone, multiple studies have noted superior visual results with combination intravitreal anti-VEGF and PDT [89,93]. In addition, the rate of anti-VEGF resistance has been higher in PCV than in other eyes with eAMD which may partially explain the superior visual response of PCV to combination therapy [94,95]. The rate of anti-VEGF resistance and significant benefit with the addition of PDT are reasons to consider the possibility of PCV in eyes diagnosed with eAMD that do not respond to initial intravitreal anti-VEGF treatment. 
Table 1. Miscellaneous Treatments of Anti-VEGF-Resistant Exudative Macular Degeneration.

\begin{tabular}{|c|c|c|c|c|c|}
\hline Authors & Publication Year & Intervention & \# of Eyes & Study Design & Findings \\
\hline Lee et al. [96] & 2019 & Dorzolamide-Timolol & 15 & $\begin{array}{l}\text { Interventional Case } \\
\text { Series }\end{array}$ & $\begin{array}{l}\text { Following four months of combination intravitreal anti-VEGF } \\
\text { injections and dorzolamide-timolol found significant } \\
\text { improvement in macular thickening, but no change in } \\
\text { visual acuity. }\end{array}$ \\
\hline Li et al. [97] & 2017 & $\begin{array}{l}\text { Topical Nonsteroidal } \\
\text { Anti-Inflammatory Drugs } \\
\text { (NSAIDs) }\end{array}$ & & Meta-Analysis & $\begin{array}{l}\text { These studies were not evaluating anti-VEGF-resistant eyes. Six } \\
\text { studies included utilizing either ketorolac four times a day or } \\
\text { bromfenac twice a day along with PRN anti-VEGF injections } \\
\text { compared to anti-VEGF monotherapy. Significantly fewer } \\
\text { injections required with bromfenac co-treatment, significantly } \\
\text { greater decrease in macular thickness with any NSAID and no } \\
\text { change in visual acuity. }\end{array}$ \\
\hline Zur et al. [98] & 2015 & $\begin{array}{l}\text { Epimacular Strontium-90 } \\
\text { Brachytherapy }\end{array}$ & 22 & Retrospective & $\begin{array}{l}\text { No significant change in macular thickness or visual acuity one } \\
\text { year after treatment. }\end{array}$ \\
\hline Zhao et al. [99] & 2019 & Oral Spironolactone & 21 & Retrospective & $\begin{array}{l}\text { Concurrently received oral spironolactone with intravitreal } \\
\text { anti-VEGF injections with significant improvement in macular } \\
\text { thickness that reversed with discontinuation of spironolactone. } \\
\text { No change in visual acuity throughout study. }\end{array}$ \\
\hline Peyman et al. [100] & 2011 & $\begin{array}{l}\text { Oscillatory Transpupillary } \\
\text { Thermotherapy }\end{array}$ & 4 & Case Series & $\begin{array}{l}\text { One eye with visual acuity improvement } 20 / 60 \text { to } 20 / 30 \text { with } \\
\text { unchanged visual acuity in other eyes after an average of one } \\
\text { year of follow-up. }\end{array}$ \\
\hline $\begin{array}{l}\text { Shah and Haller } \\
\text { [101] }\end{array}$ & 2012 & $\begin{array}{l}\text { Pars Plana Vitrectomy for } \\
\text { Vitreomacular Traction }\end{array}$ & 1 & Case Report & Visual acuity improved from $20 / 200$ to $20 / 100$. \\
\hline Kimura et al. [102] & 2016 & $\begin{array}{l}\text { Pars Plana Vitrectomy for } \\
\text { Vitreomacular Traction or } \\
\text { Epiretinal Membrane }\end{array}$ & 6 & Case Series & $\begin{array}{l}\text { Significant improvement in macular thickness and improved } \\
\text { responsiveness to intravitreal anti-VEGF injections. No change in } \\
\text { visual acuity. }\end{array}$ \\
\hline Zheng et al. [34] & 2016 & PDGF & & $\begin{array}{l}\text { Cultured Cells and } \\
\text { Mouse Model }\end{array}$ & $\begin{array}{l}\text { Upregulation of PDGF occurs with VEGF blockade which may } \\
\text { contribute to anti-VEGF resistance. Theorize that combination } \\
\text { treatment of VEGF and PDGF may counteract this resistance. }\end{array}$ \\
\hline Zhu et al. [103] & 2020 & $\begin{array}{l}\text { Apolipoprotein A-1 Binding } \\
\text { Protein }\end{array}$ & & Mouse Model & $\begin{array}{l}\text { Cholesterol-laden macrophages tied to anti-VEGF resistance. } \\
\text { Improved response to intravitreal anti-VEGF injections when } \\
\text { combined with apolipoprotein A-1 binding protein which } \\
\text { increases removal of cholesterol from macrophages to decrease } \\
\text { its activity. }\end{array}$ \\
\hline
\end{tabular}




\section{Diabetic Retinopathy and Diabetic Macular Edema}

\subsection{Steroids}

Intravitreal steroids have served an important role in the treatment of diabetic macular edema (DME) for many years, preceding the use of intravitreal anti-VEGF injections by a number of years [104-106]. The initial research utilized the IVTA injection, but in more recent years the availability of the DEX implant has provided a longer-term option for steroid therapy. In the treatment of DME, steroids act as an anti-inflammatory which helps to downregulate both pro-inflammatory and pro-angiogenic mediators in the eye that are paramount to the development of edema. As was the case for eAMD, intravitreal anti-VEGF therapy remains the standard of care for DME; however, many have utilized intravitreal steroid therapy to treat those who are resistant to such treatment.

Multiple investigators have evaluated both IVTA and DEX in the treatment of antiVEGF-resistant DME. Kim et al. retrospectively evaluated 20 eyes with anti-VEGF-resistant DME treated with a single IVTA injection. These eyes experienced a significant improvement in both macular thickness and visual acuity at three months after treatment [107]. Jeon and Lee prospectively evaluated 20 eyes with anti-VEGF-resistant DME treated with a single IVTA and followed for three months after treatment. Their results showed significant improvements in both macular thickness and visual acuity at one and two months; however, the visual acuity improvement diminished at three months. Visual acuity improved from 47.1 to 53.3 letters at two months but decreased to 50.9 letters at three months [108]. Both of these studies support the benefit of IVTA as an alternative for anti-VEGF-resistant eyes, but not unexpectedly, repeated therapy is likely necessary. In the case of steroid therapy, repeated intravitreal injections do carry the additional risks of glaucoma and cataract progression $[109,110]$.

The FDA approval of DEX for the treatment of DME offered another intravitreal steroid alternative to IVTA with the benefit of an extended therapeutic window. Multiple studies have investigated the use of DEX in the treatment of anti-VEGF-resistant DME. In several retrospective studies of anti-VEGF-resistant eyes, a single DEX implant was noted to improve both macular thickness and visual acuity for three months following treatment [16,111-116]. The visual acuity improvement waned by six months in those studies with sufficiently long follow-up [111,112]. Hatz et al. retrospectively evaluated two DEX implants separated by an average of four months in anti-VEGF-resistant DME with significant improvements in visual acuity and macular thickness noted [117]. Iacono et al. also evaluated anti-VEGF-resistant DME in 13 eyes treated with PRN DEX over one year of follow-up with significant improvements in visual acuity and macular thickness observed [118]. In the only prospective study of DEX implant monotherapy in anti-VEGF-resistant DME, Lazic et al. treated 16 eyes with a single DEX implant and reported significant improvements in macular thickness at one, two and three months. Visual acuity improved at one, two and three months as well but only significantly at two months (baseline: 20/69, one month: 20/58, two months: 20/51, three months: 20/53) [18]. Busch et al. performed the only comparative trial of DEX implants versus continued intravitreal anti-VEGF therapy in eyes with DME and an initial suboptimal response to anti-VEGF treatment. A total of 87 eyes were included with 44 eyes treated with anti-VEGF monotherapy throughout, 29 switched to DEX implant after a poor initial response to the loading dose and 14 switched after one year of anti-VEGF monotherapy. The eyes treated with DEX implants were also treated with anti-VEGF therapy concurrently and received between one to three DEX implants annually. At the culmination of the two years of follow-up, both the early and late eyes switched to the DEX implant demonstrated improvements in visual acuity and macular thickness greater than those appreciated in the anti-VEGF monotherapy group [119]. These studies overwhelmingly demonstrate the benefits of DEX implants in eyes with DME resistant to anti-VEGF therapy alone. Despite all of this strong evidence, the only randomized controlled trial with the DEX implant in anti-VEGF-resistant DME did not have such overwhelmingly positive results. Over 24 weeks, 65 eyes treated with the DEX implant and PRN IVR were compared to 51 eyes re- 
ceiving PRN IVR monotherapy. There was a significantly greater improvement in macular thickness in the combination group but no difference in the improvement in visual acuity across cohorts. An important note, however, is that the combination group had a much higher percentage of patients experiencing large improvements in vision with $\geq 10$ letters of improvement noted in $33 \%$ of the combination treatment eyes compared to just $16 \%$ of those treated with monotherapy. The poor mean visual acuity response in the combination group may be, in part, due to cataract progression resulting in significant vision loss (7 of 8 eyes with $a \geq 2$ line decrease were phakic in the combination group) [120]. Patients with anti-VEGF-resistant DME appear to benefit from the addition of the DEX implant [121], but given the need for repeated treatments every four to six months, its greatest benefit is likely as an adjunctive therapy with intravitreal anti-VEGF injections.

There are two other extended-release steroid implants available that utilize fluocinolone acetonide (FA). The $0.59 \mathrm{mg}$ intravitreal FA implant (Retisert; Bausch + Lomb; Rochester, NY, USA) requires surgical implantation but can provided years of therapy, whereas the more recently developed $0.19 \mathrm{mg}$ intravitreal FA implant (Iluvien; Alimera Sciences Inc; Alpharetta, GA, USA) is an injectable implant that can be performed in clinic which can also last for a year or longer. Multiple studies have investigated the intravitreal FA implant in the treatment of anti-VEGF-resistant DME with beneficial, sustained visual acuity and macular thickness results [122-128]. Compared to the DEX implant, the $0.19 \mathrm{mg}$ intravitreal FA implant offers continuous steroid therapy for longer treatment intervals (about 4 months compared to 8-24 months). Similar to previously discussed intravitreal steroid treatments, the FA implant appears to be most effective when supplemented with continued intravitreal anti-VEGF injections.

As an alternative to intravitreal steroid therapy, posterior subtenon triamcinolone has also been utilized in the treatment of DME with mixed results $[129,130]$. Eriş et al. retrospectively compared the treatment of anti-VEGF-resistant DME with combination posterior subtenon triamcinolone and intravitreal anti-VEGF versus anti-VEGF monotherapy. The 38 eyes treated with combination therapy (including a single posterior subtenon triamcinolone and PRN anti-VEGF) achieved a significant improvement in visual acuity and macular thickness after six months. The 34 eyes treated with PRN anti-VEGF as monotherapy were noted to have nonsignificant improvements in both measures [131]. There has been some evidence that the posterior subtenon application of steroids results in less steroid responsive intraocular pressure elevation than intravitreal steroids [132,133]. Although the research is limited to this single study, the use of posterior subtenon triamcinolone may be a useful adjunctive therapy in anti-VEGF-resistant DME if concern exists for steroid induced glaucoma.

\subsection{Laser Photocoagulation}

The use of thermal laser photocoagulation has been around for decades in the treatment of retinal diseases, especially vascular disorders such as diabetic retinopathy. Various forms of thermal laser photocoagulation have been utilized to treat different aspects of these diseases. Panretinal photocoagulation (PRP) applies equally spaced laser burns to the retinal periphery in eyes with proliferative diabetic retinopathy (PDR). These are applied to ischemic areas of the retina which effectively destroys those areas and halts the eyes drive to produce VEGF. Focal laser photocoagulation applies gentler, lower energy laser to leaking macular microaneurysms which are key to the development of DME. Grid laser photocoagulation similarly applies gentler, lower energy laser to diffuse areas of macular leakage instead of specifically targeting leaking microaneurysms. Finally, the more recently developed subthreshold or micropulse laser provides short, repeated bursts of laser energy which allows the tissue to cool prior to the application of further laser energy. This is different to traditional laser photocoagulation which provides a continuous wave of laser energy without requiring a cooling period between applications and thus limits the spread of laser damage to the surrounding structures. Micropulse laser has been utilized similarly to grid laser photocoagulation in the treatment of DME. 
In eyes with PDR, multiple studies have shown better visual acuity benefits from the use of intravitreal anti-VEGF therapy over PRP treatment [7,134]. As discussed above, the driving force for the development of PDR is VEGF which results in retinal neovascularization. Regular application of intravitreal anti-VEGF injections can keep this at bay. A significant concern in the treatment of PDR, however, is the potential for catastrophic progression and profound vision loss in the absence of regular follow-up with the development of vitreous hemorrhage or tractional retinal detachment. Intravitreal anti-VEGF injections rely upon regular treatment to keep the neovascularization of PDR under control; thus, it is not a surprise that studies have shown significantly worse outcomes in PDR eyes lost to follow-up treated with anti-VEGF compared to PRP [135]. Hence, despite studies showing improved visual results with intravitreal anti-VEGFs, the use of PRP still remains commonplace and would be an obvious choice in an eye with anti-VEGF-resistant PDR.

The initial Early Treatment Diabetic Retinopathy Study demonstrated the benefit of laser photocoagulation in the treatment of clinically significant macular edema [136]. As has been the case for many of the previously discussed treatment modalities, it has largely been replaced by intravitreal anti-VEGF therapy as first line therapy for DME. While there has not been any studies to evaluate the use of focal or grid laser photocoagulation in the treatment of anti-VEGF-resistant DME, numerous studies have evaluated its use in combination with anti-VEGF therapy [137-140]. Although these results have not demonstrated improved outcomes with combination treatment compared to intravitreal anti-VEGF monotherapy, there has been some evidence of a decreased anti-VEGF burden with combination therapy $[137,138]$. These findings support a theoretical benefit of focal or grid laser photocoagulation in anti-VEGF-resistant DME.

As previously noted, micropulse laser offers an approach to the treatment of DME similar to grid laser photocoagulation with less collateral damage to the precious macular tissue. Multiple studies have demonstrated a significant decrease in the number of intravitreal anti-VEGF injections when combined with micropulse therapy to treat DME [141,142]. In the only study evaluating micropulse laser in anti-VEGF-resistant DME, 21 patients had one eye randomly assigned to micropulse laser with intravitreal anti-VEGF and the other eye treated with anti-VEGF monotherapy. At three months, visual acuity decreased significantly in the anti-VEGF monotherapy group (20/100 to 20/123) and increased significantly in the combination group (20/129 to 20/83) [143]. This therapy is a relatively recent advancement; hence, there is only limited research and long-term outcomes are unclear. Although, these results provide reason for optimism about its benefit in antiVEGF-resistant DME.

Overall, laser photocoagulation, in all of its forms, has an important role in the treatment of diabetic retinopathy and DME especially as an alternative to intravitreal anti-VEGF in eyes that are resistant.

\subsection{Miscellaneous Treatment Considerations}

As discussed with anti-VEGF-resistant eAMD, some cases will have improved responses to a switch in anti-VEGF agent. This possibility has also been evaluated in antiVEGF-resistant DME. Multiple studies have investigated switching from IVR and/or IVB to IVA in eyes with anti-VEGF-resistant DME. These studies have demonstrated significant improvements in visual acuity and macular thickness with this switch while utilizing either a standard every eight week or PRN dosing regimen [144-146].

The topical application of medication provides an additional therapeutic route in these anti-VEGF-resistant eyes. Various studies have evaluated the efficacy of topical anti-glaucoma medications as an adjuvant therapy to intravitreal anti-VEGF injections with mixed results. In a randomized controlled trial, the carbonic anhydrase inhibitor (CAI), dorzolamide (Merck \& Co; Kenilworth, NJ, USA), was applied to one eye of 16 patients receiving monthly IVB in both eyes for DME. Comparison of the eyes treated with and without dorzolamide at three months did not demonstrate a difference in visual acuity or macular thickness results [147]. On the other hand, a similar study with topical 
dorzolamide-timolol (Akorn; Lake Forest, IL, USA) in 11 patients demonstrated significantly better visual acuity and macular thickness after three months in the eyes receiving topical treatment [147]. Multiple theories exist as to why such medications may provide improved results in combination with anti-VEGF therapy. Topical dorzolamide as well as oral CAIs have found utility in the treatment of other causes of macular edema such as retinitis pigmentosa $[148,149]$. Rat models have found carbonic anhydrase enzymes on the cell membranes of Muller cells and the retinal pigment epithelium [150]. Thus, it is possible that the dehydrating capacity of CAIs has activity on these retinal cells resulting in decreased macular edema. The second component of this combination drop, timolol, is a beta blocker which has been theorized to play a role in the downregulation of VEGF [151]. It appears that this combination therapy plays a synergistic role with intravitreal anti-VEGF therapy to accentuate its efficacy. Although studies have not evaluated the benefit of topical anti-glaucoma medications in anti-VEGF-resistant DME, these results appear to support its utility in such situations.

Another commonly used topical medication in the treatment of retinal diseases are nonsteroidal anti-inflammatory drugs (NSAIDs). We have previously reported of a single case of DME responsive to combination topical NSAID, steroid and CAI and subsequently maintained on the topical NSAID alone for a year [152]. In a cohort of 17 eyes with treatment naïve DME, Pinna et al. found significant improvements in macular thickness after administration of topical bromfenac (Bausch + Lomb; Rochester, NY, USA) twice daily, but no significant change noted in visual acuity [153]. Multiple studies have also evaluated the use of intravitreal NSAIDs in the form of diclofenac (Troge Medical GMBH, Hamburg, Germany) compared to and in combination with IVB. Overall, these studies have shown visual and macular thickness benefits to such treatment which, in some cases, was superior to IVB monotherapy [154-156]. These studies were all performed in treatment naïve eyes, but the evidence of the benefit of NSAID therapy as a possible adjuvant treatment with anti-VEGF injections appears consistent. Topical application of such medications comes with less significant side effects especially in the short term, most concerning corneal toxicity, so a trial of therapy may be of benefit in such anti-VEGF-resistant eyes with DME.

Some investigators have evaluated other therapeutic options not traditionally applied to retinal diseases as well, including methotrexate and interferon alpha. Methotrexate is an antimetabolite that is commonly used systemically as an immunosuppressive agent. Previously, intravitreal methotrexate has been applied as the treatment of intraocular lymphoma and proliferative vitreoretinopathy $[157,158]$. Interferon alpha is another commonly used systemic medication in the treatment of numerous hematologic conditions. Topical application has been used for the treatment of conjunctival malignancies and even in pterygium surgery to help prevent recurrence $[159,160]$. Both intravitreal methotrexate and topical interferon alpha have similar theoretical benefits in the treatment of anti-VEGFresistant DME as both have anti-inflammatory properties similar to the steroid therapy discussed previously. Falavarjani et al. prospectively evaluated 18 anti-VEGF-resistant eyes with DME treated with a single intravitreal methotrexate injection and noted significant improvement in visual acuity at one, three and six months. There was no significant change noted in macular thickness [161]. Similarly, Maleki et al. studied five eyes with anti-VEGF-resistant DME treated with topical interferon alpha initially four times a day for two to three months with a slow taper thereafter. Macular thickness improved significantly in these eyes after one month and all eyes were noted to have stable or improved visual acuity as well [162]. These alternative anti-inflammatory therapies have only been utilized in the above limited reports, but these results appear to demonstrate a need for further research as a benefit in anti-VEGF-resistant eyes appears to exist.

\section{Retinal Vein Occlusions}

Steroids

Similar to the case with DME, the use of intravitreal steroid therapy in the treatment of RVOs has a long history. The initial SCORE studies (Standard Care vs. Corticosteroid 
for Retinal Vein Occlusion) demonstrated the benefit of IVTA in the treatment of central RVOs (CRVOs) but did not report significant benefit in branch RVOs (BRVOs) $[163,164]$. Once again, the anti-inflammatory and anti-angiogenic capacity of steroids such as IVTA and DEX assist in the resolution of the macular edema that results from RVOs. The use of intravitreal anti-VEGF injections has largely replaced steroids as the primary treatment of RVOs, but there still exists a subset of eyes that will be resistant to such therapy.

There has been a number of studies exploring the use of the DEX implants in the treatment of anti-VEGF-resistant RVOs demonstrating an overall benefit for such therapy. Yong et al. reported on one eye with anti-VEGF-resistant CRVO with a significant improvement noted in both visual acuity and macular thickness six months after a single DEX implant [165]. Ip et al. prospectively evaluated 14 eyes with either a CRVO or hemiretinal RVO resistant to IVA therapy switched to treatment with the DEX implant. These eyes received either one or two implants over a six-month follow-up. No significant improvement in visual acuity or macular thickness were noted in these eyes [166]. Georgalas et al. also prospectively evaluated anti-VEGF-resistant eyes with either CRVO (10 eyes) or BRVO (13 eyes) over a one-year study. Treatment was performed every six months PRN with a significant improvement in macular thickness noted in both groups at one year. Visual acuity, however, only improved significantly in the BRVO cohort with a nonsignificant improvement noted in the CRVO cohort [167]. In another retrospective study, Wolfe et al. treated 14 eyes with anti-VEGF-resistant RVOs and noted a significant improvement in both visual acuity and macular thickening. An interesting additional point noted by the authors was the correlation between an insufficient response in macular thickening on OCT (defined as $\leq 25 \%$ reduction in central macular thickness) one month after the first intravitreal anti-VEGF injection and long-term unresponsiveness to anti-VEGF therapy [168]. Finally, we reported our experience in a prospective study of 10 eyes with RVOs (9 with BRVO and 1 with CRVO) resistant to anti-VEGF injections treated with DEX implants every four months or PRN for 1 year. These eyes experienced significant improvements in macular thickening and on multifocal electroretinography testing, but visual acuity results were limited by cataract progression [169]. Figure 2 demonstrates the significant improvement in macular edema and visual acuity experienced in an eye with BRVO unresponsive to numerous anti-VEGF injections after a single DEX implant. Overall, eyes with BRVO resistant to anti-VEGF appear to show a substantial response to the DEX implant whereas the response to the DEX implant in eyes with CRVO is less robust.
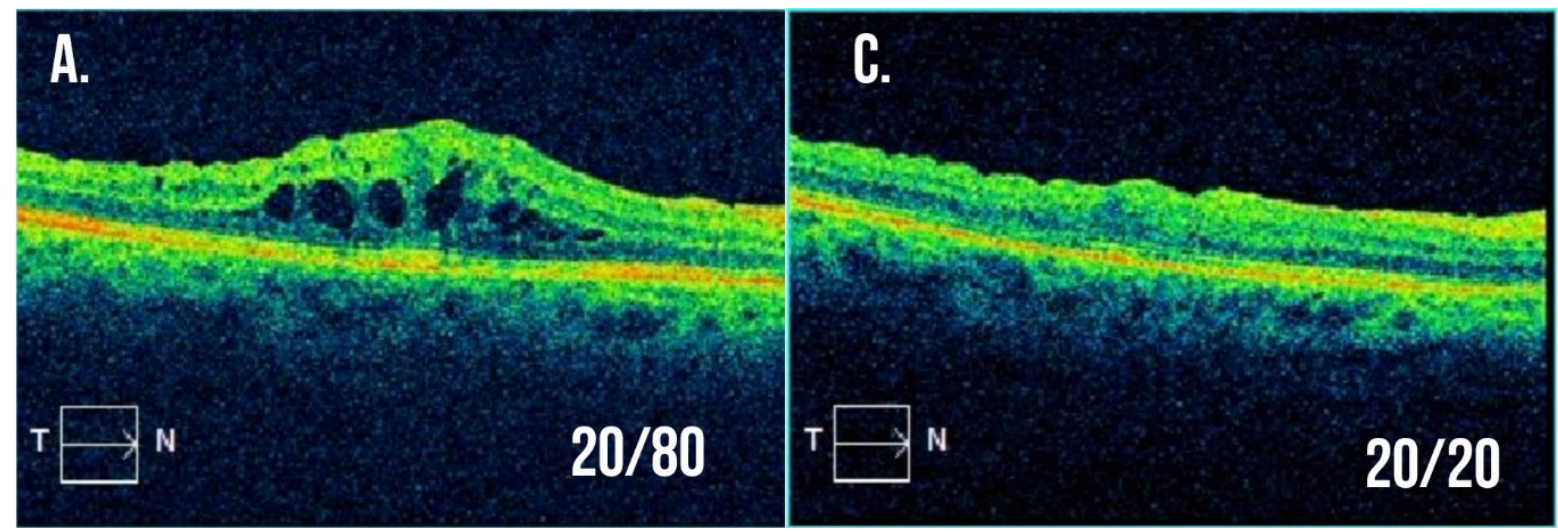

Figure 2. Cont. 


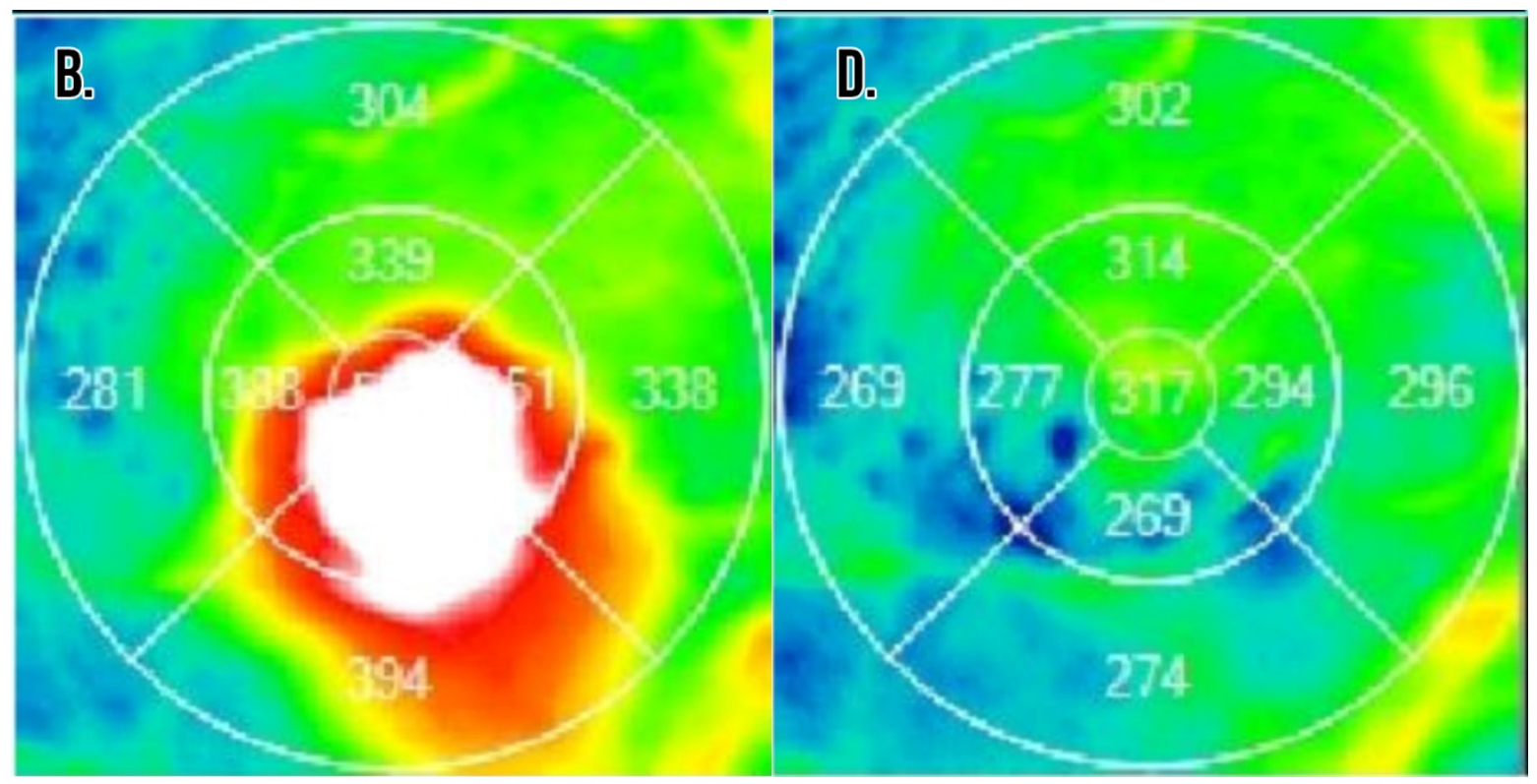

Figure 2. Example optical coherence tomography for a patient with branch retinal vein occlusion resistant to intravitreal anti-VEGF injections. (A,B) Macular cross-section and thickness map following multiple intravitreal anti-VEGF injections with visual acuity 20/80 and significant macular edema present. The decision was made to treat with a combination of intravitreal dexamethasone implant and anti-VEGF injection at this visit. (C,D) Macular cross-section and thickness map two months after the combination treatment with visual acuity now 20/20 and resolution of macular edema.

\section{Future Considerations-Ranibizumab Port Delivery System}

The development of anti-VEGF resistance in many eyes may in part be due to diminishing levels of anti-VEGF which naturally occurs between treatments. As discussed above, some have counteracted this by decreasing treatment intervals or increasing treatment doses. On the horizon is another alternative solution to this troubling scenario, the ranibizumab port delivery system (RPDS). The RPDS is a surgically implanted refillable reservoir that continuously delivers ranibizumab to the vitreous cavity. A phase 3 clinical study is ongoing (ClinicalTrials.gov: NCT03677934), but earlier studies have demonstrated its safety with comparable visual acuity and macular thickness results to IVR therapy in the treatment of eAMD $[170,171]$. This technology's capacity to continuously deliver anti-VEGF may be paramount to overcoming anti-VEGF resistance in all the previously discussed diseases.

Although targeting VEGF continues to be the mainstay of therapy, as discussed above, there are numerous pathways and targets involved in the development of macular edema in retinal diseases. Research is ongoing into investigational drugs that can utilize these alternative pathways including angiopoietin and CCR3 [172-174]. Such pathways could provide therapeutic options that can be used alone or in combination with anti-VEGF to potentially improve effectiveness or prolong duration of response [175]. A Better understanding of which of these pathways underlie the development of anti-VEGF resistance will also be a significant step forward in the successful treatment of this challenging situation.

\section{Conclusions}

Treatment resistance to intravitreal anti-VEGF injections represents a clinical dilemma for eAMD, diabetic retinopathy and RVOs. Various alternative treatment options exist with varying degrees of success and selection of the best treatment approach must largely be determined based on the clinical scenario. An important consideration before initiating one of these alternative approaches is the patient's adherence to scheduled injection appointments. Certain patients cannot tolerate even being a few days late for their scheduled injection so it may be necessary to first introduce a strict injection schedule, with one injection every four weeks. Following this, many patients may respond to a simple switch 
of anti-VEGF agents while others may require more regular injections or even injections of larger doses than utilized in standard protocols. Beyond that, the addition of supplemental intravitreal steroids either in the form of IVTA, DEX implant or FA implant appears to be of benefit most often in the retinal vascular diseases. Laser therapy (in the form of PDT in eAMD or thermal laser in diabetic retinopathy) is useful when steroid therapy fails or is contraindicated by other patient characteristics such as poorly controlled glaucoma (Figure 3). Finally, research is continuing into novel treatment options that may provide the much-needed therapeutic agent in the continued battle against these blinding conditions.

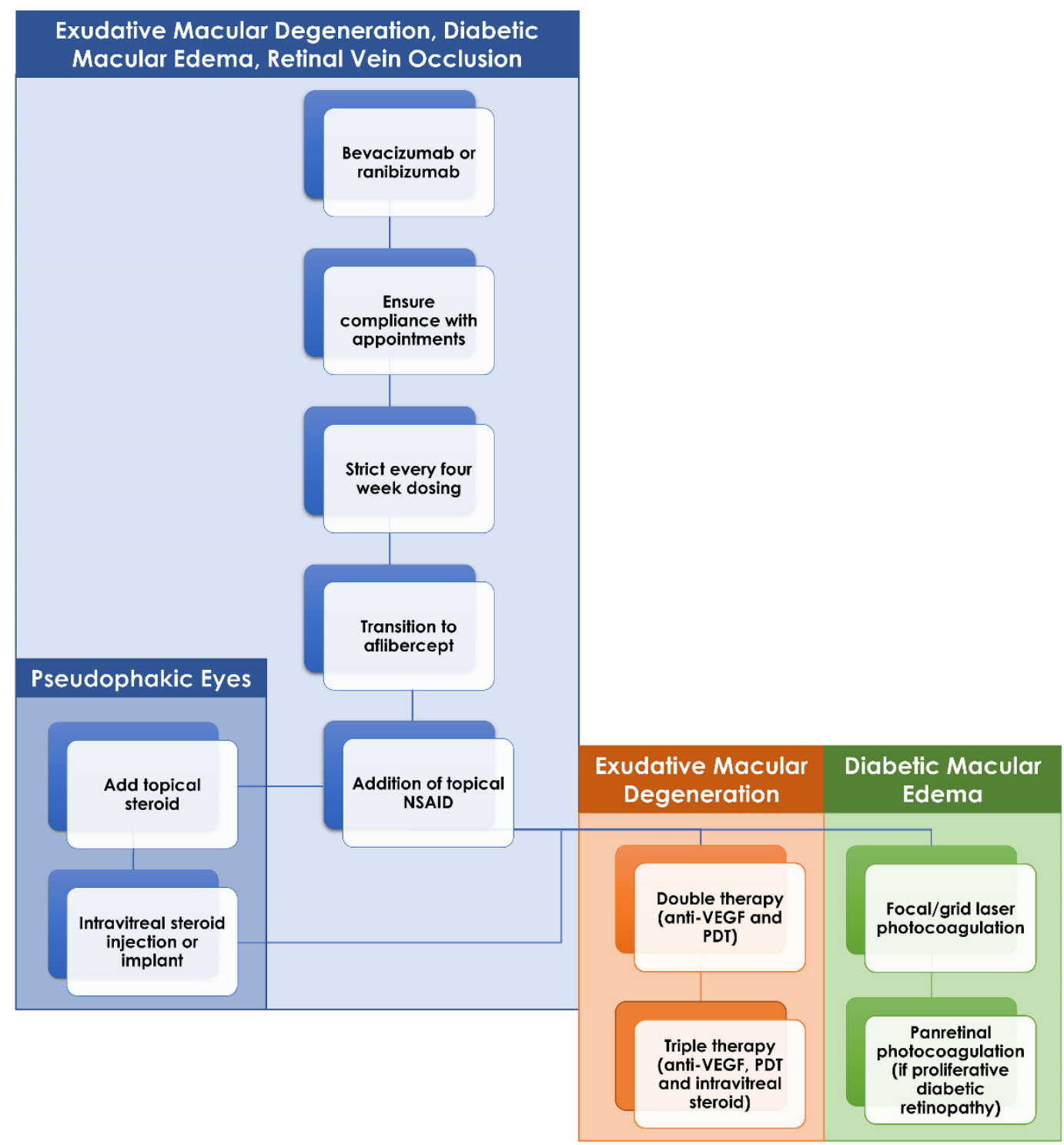

Figure 3. Flow chart of recommend management of anti-VEGF-resistant macular edema in exudative macular degeneration (eAMD), diabetic retinopathy and retinal vein occlusions. If initial therapy with bevacizumab or ranibizumab fails, then ensuring patient adherence to injection schedule is a key first step. Following this would be a strict injection schedule, one injection every four weeks, and transition to aflibercept if still active. Topical therapy with nonsteroidal anti-inflammatory drugs and, if pseudophakic, steroids can be initiated if the macular edema remains resistant. Intravitreal steroid injections or implants can be added in those eyes without contraindications. Finally, in eAMD and diabetic retinopathy, the addition of laser therapy (photodynamic therapy for eAMD and focal/grid laser or panretinal photocoagulation in diabetic retinopathy) can be considered in those eyes that remain resistant to all of the aforementioned treatments. 
Funding: This research received no external funding.

Conflicts of Interest: The authors declare no conflict of interest.

\section{References}

1. Ishibashi, T.; Hata, Y.; Yoshikawa, H.; Nakagawa, K.; Sueishi, K.; Inomata, H. Expression of vascular endothelial growth factor in experimental choroidal neovascularization. Graefes Arch. Clin. Exp. Ophthalmol. 1997, 235, 159-167. [CrossRef] [PubMed]

2. Nguyen, Q.D.; Tatlipinar, S.; Shah, S.M.; Haller, J.A.; Quinlan, E.; Sung, J.; Zimmer-Galler, I.; Do, D.V.; Campochiaro, P.A. Vascular endothelial growth factor is a critical stimulus for diabetic macular edema. Am. J. Ophthalmol. 2006, 142, 961-969. [CrossRef] [PubMed]

3. Miller, J.W.; Le Couter, J.; Strauss, E.C.; Ferrara, N. Vascular endothelial growth factor a in intraocular vascular disease. Ophthalmology 2013, 120, 106-114. [CrossRef] [PubMed]

4. Heier, J.S.; Brown, D.M.; Chong, V.; Korobelnik, J.F.; Kaiser, P.K.; Nguyen, Q.D.; Kirchhof, B.; Ho, A.; Ogura, Y.; Yancopoulos, G.D.; et al. Intravitreal aflibercept (VEGF trap-eye) in wet age-related macular degeneration. Ophthalmology 2012, 119, $2537-2548$. [CrossRef] [PubMed]

5. Brown, D.M.; Campochiaro, P.A.; Singh, R.P.; Li, Z.; Gray, S.; Saroj, N.; Rundle, A.C.; Rubio, R.G.; Murahashi, W.Y. Ranibizumab for macular edema following central retinal vein occlusion: Six-month primary end point results of a phase III study. Ophthalmology 2010, 117, 1124-1133.e1121. [CrossRef] [PubMed]

6. Gillies, M.C.; Hunyor, A.P.; Arnold, J.J.; Guymer, R.H.; Wolf, S.; Ng, P.; Pecheur, F.L.; McAllister, I.L. Effect of Ranibizumab and Aflibercept on Best-Corrected Visual Acuity in Treat-and-Extend for Neovascular Age-Related Macular Degeneration: A Randomized Clinical Trial. JAMA Ophthalmol. 2019, 137, 372-379. [CrossRef] [PubMed]

7. Gross, J.G.; Glassman, A.R.; Liu, D.; Sun, J.K.; Antoszyk, A.N.; Baker, C.W.; Bressler, N.M.; Elman, M.J.; Ferris, F.L., 3rd; Gardner, T.W.; et al. Five-Year Outcomes of Panretinal Photocoagulation vs Intravitreous Ranibizumab for Proliferative Diabetic Retinopathy: A Randomized Clinical Trial. JAMA Ophthalmol. 2018, 136, 1138-1148. [CrossRef] [PubMed]

8. Wells, J.A.; Glassman, A.R.; Ayala, A.R.; Jampol, L.M.; Bressler, N.M.; Bressler, S.B.; Brucker, A.J.; Ferris, F.L.; Hampton, G.R.; Jhaveri, C.; et al. Aflibercept, Bevacizumab, or Ranibizumab for Diabetic Macular Edema: Two-Year Results from a Comparative Effectiveness Randomized Clinical Trial. Ophthalmology 2016, 123, 1351-1359. [CrossRef] [PubMed]

9. Bressler, N.M.; Beaulieu, W.T.; Maguire, M.G.; Glassman, A.R.; Blinder, K.J.; Bressler, S.B.; Gonzalez, V.H.; Jampol, L.M.; Melia, M.; Sun, J.K.; et al. Early Response to Anti-Vascular Endothelial Growth Factor and Two-Year Outcomes Among Eyes With Diabetic Macular Edema in Protocol T. Am. J. Ophthalmol. 2018, 195, 93-100. [CrossRef]

10. Gonzalez, V.H.; Campbell, J.; Holekamp, N.M.; Kiss, S.; Loewenstein, A.; Augustin, A.J.; Ma, J.; Ho, A.C.; Patel, V.; Whitcup, S.M.; et al. Early and Long-Term Responses to Anti-Vascular Endothelial Growth Factor Therapy in Diabetic Macular Edema: Analysis of Protocol I Data. Am. J. Ophthalmol. 2016, 172, 72-79. [CrossRef] [PubMed]

11. Rich, R.M.; Rosenfeld, P.J.; Puliafito, C.A.; Dubovy, S.R.; Davis, J.L.; Flynn, H.W., Jr.; Gonzalez, S.; Feuer, W.J.; Lin, R.C.; Lalwani, G.A.; et al. Short-term safety and efficacy of intravitreal bevacizumab (Avastin) for neovascular age-related macular degeneration. Retina 2006, 26, 495-511. [CrossRef]

12. Martin, D.F.; Maguire, M.G.; Ying, G.S.; Grunwald, J.E.; Fine, S.L.; Jaffe, G.J. Ranibizumab and bevacizumab for neovascular age-related macular degeneration. N. Engl. J. Med. 2011, 364, 1897-1908. [CrossRef] [PubMed]

13. Amoaku, W.M.; Chakravarthy, U.; Gale, R.; Gavin, M.; Ghanchi, F.; Gibson, J.; Harding, S.; Johnston, R.L.; Kelly, S.P.; Lotery, A.; et al. Defining response to anti-VEGF therapies in neovascular AMD. Eye 2015, 29, 721-731. [CrossRef] [PubMed]

14. Shah, A.R.; Yonekawa, Y.; Todorich, B.; Van Laere, L.; Hussain, R.; Woodward, M.A.; Abbey, A.M.; Wolfe, J.D. Prediction of Anti-VEGF Response in Diabetic Macular Edema After 1 Injection. J. Vitreoretin. Dis. 2017, 1, 169-174. [CrossRef] [PubMed]

15. Thomas, B.J.; Yonekawa, Y.; Wolfe, J.D.; Hassan, T.S. Contralateral eye-to-eye comparison of intravitreal ranibizumab and a sustained-release dexamethasone intravitreal implant in recalcitrant diabetic macular edema. Clin. Ophthalmol. 2016, 10, 1679-1684. [CrossRef] [PubMed]

16. Bansal, P.; Gupta, V.; Gupta, A.; Dogra, M.R.; Ram, J. Efficacy of Ozurdex implant in recalcitrant diabetic macular edema-A single-center experience. Int. Ophthalmol. 2016, 36, 207-216. [CrossRef]

17. Medeiros, M.D.; Alkabes, M.; Navarro, R.; Garcia-Arumi, J.; Mateo, C.; Corcostegui, B. Dexamethasone intravitreal implant in vitrectomized versus nonvitrectomized eyes for treatment of patients with persistent diabetic macular edema. J. Ocul. Pharmacol. Ther. 2014, 30, 709-716. [CrossRef] [PubMed]

18. Lazic, R.; Lukic, M.; Boras, I.; Draca, N.; Vlasic, M.; Gabric, N.; Tomic, Z. Treatment of anti-vascular endothelial growth factor-resistant diabetic macular edema with dexamethasone intravitreal implant. Retina 2014, 34, 719-724. [CrossRef]

19. Cohen, M.N.; Houston, S.K.; Juhn, A.; Ho, A.C.; Regillo, C.D.; Vander, J.; Chiang, A. Effect of aflibercept on refractory macular edema associated with central retinal vein occlusion. Can. J. Ophthalmol. 2016, 51, 342-347. [CrossRef]

20. Eadie, J.A.; Ip, M.S.; Kulkarni, A.D. Response to aflibercept as secondary therapy in patients with persistent retinal edema due to central retinal vein occlusion initially treated with bevacizumab or ranibizumab. Retina 2014, 34, 2439-2443. [CrossRef]

21. Lehmann-Clarke, L.; Dirani, A.; Mantel, I.; Ambresin, A. The effect of switching ranibizumab to aflibercept in refractory cases of macular edema secondary to ischemic central vein occlusion. Klin. Monbl. Augenheilkd. 2015, 232, 552-555. [CrossRef] [PubMed]

22. Noma, H.; Yasuda, K.; Shimura, M. Involvement of Cytokines in the Pathogenesis of Diabetic Macular Edema. Int. J. Mol. Sci. 2021, 22, 3427. [CrossRef] [PubMed] 
23. Penn, J.S.; Madan, A.; Caldwell, R.B.; Bartoli, M.; Caldwell, R.W.; Hartnett, M.E. Vascular endothelial growth factor in eye disease. Prog. Retin. Eye Res. 2008, 27, 331-371. [CrossRef] [PubMed]

24. Noma, H.; Mimura, T.; Eguchi, S. Association of Inflammatory Factors With Macular Edema in Branch Retinal Vein Occlusion. JAMA Ophthalmol. 2013, 131, 160-165. [CrossRef] [PubMed]

25. Campa, C.; Costagliola, C.; Incorvaia, C.; Sheridan, C.; Semeraro, F.; De Nadai, K.; Sebastiani, A.; Parmeggiani, F. Inflammatory Mediators and Angiogenic Factors in Choroidal Neovascularization: Pathogenetic Interactions and Therapeutic Implications. Mediat. Inflamm. 2010, 2010, 546826. [CrossRef] [PubMed]

26. Finetti, F.; Solito, R.; Morbidelli, L.; Giachetti, A.; Ziche, M.; Donnini, S. Prostaglandin E2 regulates angiogenesis via activation of fibroblast growth factor receptor-1. J. Biol. Chem. 2008, 283, 2139-2146. [CrossRef]

27. Han, D.Y.; Cho, J.-S.; Moon, Y.-M.; Lee, H.-R.; Lee, H.-M.; Lee, B.D.; Baek, B.J. Effect of prostaglandin e2 on vascular endothelial growth factor production in nasal polyp fibroblasts. Allergy Asthma Immunol. Res. 2013, 5, 224-231. [CrossRef]

28. Wang, M.; Wang, Y.; Xie, T.; Zhan, P.; Zou, J.; Nie, X.; Shao, J.; Zhuang, M.; Tan, C.; Tan, J.; et al. Prostaglandin E2/EP2 receptor signalling pathway promotes diabetic retinopathy in a rat model of diabetes. Diabetologia 2019, 62, 335-348. [CrossRef]

29. Xie, T.; Zhang, Z.; Cui, Y.; Shu, Y.; Liu, Y.; Zou, J.; Wang, M.; Wang, Y.; Yang, Q.; Pan, X.; et al. Prostaglandin E2 promotes pathological retinal neovascularisation via EP4R-EGFR-Gab1-AKT signaling pathway. Exp. Eye Res. 2021, 205, 108507. [CrossRef]

30. Itatani, Y.; Kawada, K.; Yamamoto, T.; Sakai, Y. Resistance to Anti-Angiogenic Therapy in Cancer-Alterations to Anti-VEGF Pathway. Int. J. Mol. Sci. 2018, 19, 1232. [CrossRef]

31. Haibe, Y.; Kreidieh, M.; El Hajj, H.; Khalifeh, I.; Mukherji, D.; Temraz, S.; Shamseddine, A. Resistance Mechanisms to Antiangiogenic Therapies in Cancer. Front. Oncol. 2020, 10, 221. [CrossRef]

32. Cunningham, F.; Van Bergen, T.; Canning, P.; Lengyel, I.; Feyen, J.H.M.; Stitt, A.W. The Placental Growth Factor Pathway and Its Potential Role in Macular Degenerative Disease. Curr Eye Res. 2019, 44, 813-822. [CrossRef] [PubMed]

33. Sadiq, M.A.; Hanout, M.; Sarwar, S.; Hassan, M.; Do, D.V.; Nguyen, Q.D.; Sepah, Y.J. Platelet derived growth factor inhibitors: A potential therapeutic approach for ocular neovascularization. Saudi J. Ophthalmol. 2015, 29, 287-291. [CrossRef]

34. Zheng, L.; Zhao, C.; Du, Y.; Lin, X.; Jiang, Y.; Lee, C.; Tian, G.; Mi, J.; Li, X.; Chen, Q.; et al. PDGF-CC underlies resistance to VEGF-A inhibition and combinatorial targeting of both suppresses pathological angiogenesis more efficiently. Oncotarget 2016, 7 , 77902-77915. [CrossRef]

35. Capitão, M.; Soares, R. Angiogenesis and Inflammation Crosstalk in Diabetic Retinopathy. J. Cell Biochem. 2016, 117, $2443-2453$. [CrossRef]

36. Srividya, G.; Jain, M.; Mahalakshmi, K.; Gayathri, S.; Raman, R.; Angayarkanni, N. A novel and less invasive technique to assess cytokine profile of vitreous in patients of diabetic macular oedema. Eye 2018, 32, 820-829. [CrossRef] [PubMed]

37. Regeneron Pharmaceuticals. Eylea [Package Insert]; Regeneron Pharmaceuticals: Tarrytown, NY, USA, 2019.

38. Genentech. Lucentis [Package Insert]; Genentech: South San Francisco, CA, USA, 2017.

39. Mimouni, M.; Meshi, A.; Vainer, I.; Gershoni, A.; Koren, T.; Geffen, N.; Nemet, A.Y.; Segal, O. Bevacizumab dosing every 2 weeks for neovascular age-related macular degeneration refractory to monthly dosing. Jpn J. Ophthalmol. 2018, 62, 652-658. [CrossRef] [PubMed]

40. Witkin, A.J.; Rayess, N.; Garg, S.J.; Maguire, J.I.; Storey, P.; Kaiser, R.S.; Hsu, J.; Vander, J.F.; Ho, A.C. Alternating Bi-Weekly Intravitreal Ranibizumab and Bevacizumab for Refractory Neovascular Age-Related Macular Degeneration with Pigment Epithelial Detachment. Semin. Ophthalmol. 2017, 32, 309-315. [CrossRef] [PubMed]

41. Stewart, M.W.; Rosenfeld, P.J.; Penha, F.M.; Wang, F.; Yehoshua, Z.; Bueno-Lopez, E.; Lopez, P.F. Pharmacokinetic rationale for dosing every 2 weeks versus 4 weeks with intravitreal ranibizumab, bevacizumab, and aflibercept (vascular endothelial growth factor Trap-eye). Retina 2012, 32, 434-457. [CrossRef] [PubMed]

42. Muftuoglu, I.K.; Tsai, F.F.; Gaber, R.; Alam, M.; Meshi, A.; Freeman, W.R. High-frequency aflibercept injections in persistent neovascular age-related macular degeneration. Graefes Arch. Clin. Exp. Ophthalmol. 2017, 255, 709-717. [CrossRef] [PubMed]

43. Arcinue, C.A.; Ma, F.; Barteselli, G.; Sharpsten, L.; Gomez, M.L.; Freeman, W.R. One-year outcomes of aflibercept in recurrent or persistent neovascular age-related macular degeneration. Am. J. Ophthalmol. 2015, 159, 426-436.e422. [CrossRef] [PubMed]

44. Busbee, B.G.; Ho, A.C.; Brown, D.M.; Heier, J.S.; Suñer, I.J.; Li, Z.; Rubio, R.G.; Lai, P. Twelve-month efficacy and safety of 0.5 $\mathrm{mg}$ or $2.0 \mathrm{mg}$ ranibizumab in patients with subfoveal neovascular age-related macular degeneration. Ophthalmology 2013, 120, 1046-1056. [CrossRef]

45. Brown, D.M.; Chen, E.; Mariani, A.; Major, J.C., Jr. Super-dose anti-VEGF (SAVE) trial: 2.0 mg intravitreal ranibizumab for recalcitrant neovascular macular degeneration-primary end point. Ophthalmology 2013, 120, 349-354. [CrossRef] [PubMed]

46. Chen, E.; Mariani, A.F.; Brown, D.M. The Superdose Anti-VEGF (SAVE) Trial: 2.0-mg Intravitreal Ranibizumab for Recalcitrant Neovascular AMD, Two Year Endpoint Results. Investig. Ophthalmol. Vis. Sci. 2012, 53, 2032.

47. Wykoff, C.C.; Brown, D.M.; Chen, E.; Major, J.C.; Croft, D.E.; Mariani, A.; Wong, T.P. SAVE (Super-dose anti-VEGF) trial: 2.0 mg ranibizumab for recalcitrant neovascular age-related macular degeneration: 1-year results. Ophthalmic Surg. Lasers Imaging Retina 2013, 44, 121-126. [CrossRef] [PubMed]

48. Fung, A.T.; Kumar, N.; Vance, S.K.; Slakter, J.S.; Klancnik, J.M.; Spaide, R.S.; Freund, K.B. Pilot study to evaluate the role of high-dose ranibizumab $2.0 \mathrm{mg}$ in the management of neovascular age-related macular degeneration in patients with persistent/recurrent macular fluid $<30$ days following treatment with intravitreal anti-VEGF therapy (the LAST Study). Eye 2012, 26, 1181-1187. [CrossRef] 
49. You, Q.S.; Gaber, R.; Meshi, A.; Ramkumar, H.L.; Alam, M.; Muftuoglu, I.K.; Freeman, W.R. High-dose high-frequency aflibercept for recalcitrant neovascular age-related macular degeneration. Retina 2018, 38, 1156-1165. [CrossRef] [PubMed]

50. Kemp, A.; Preen, D.B.; Morlet, N.; Clark, A.; McAllister, I.L.; Briffa, T.; Sanfilippo, F.M.; Ng, J.Q.; McKnight, C.; Reynolds, W.; et al. Myocardial infarction after intravitreal vascular endothelial growth factor inhibitors: A whole population study. Retina 2013, 33, 920-927. [CrossRef]

51. Tolentino, M. Systemic and ocular safety of intravitreal anti-VEGF therapies for ocular neovascular disease. Surv. Ophthalmol. 2011, 56, 95-113. [CrossRef]

52. Dalvin, L.A.; Starr, M.R.; AbouChehade, J.E.; Damento, G.M.; Garcia, M.; Shah, S.M.; Hodge, D.O.; Meissner, I.; Bakri, S.J.; Iezzi, R. Association of Intravitreal Anti-Vascular Endothelial Growth Factor Therapy With Risk of Stroke, Myocardial Infarction, and Death in Patients With Exudative Age-Related Macular Degeneration. JAMA Ophthalmol. 2019, 137, 483-490. [CrossRef]

53. Zuber-Laskawiec, K.; Kubicka-Trzaska, A.; Karska-Basta, I.; Pociej-Marciak, W.; Romanowska-Dixon, B. Non-responsiveness and tachyphylaxis to anti-vascular endothelial growth factor treatment in naive patients with exudative age-related macular degeneration. J. Physiol Pharmacol. 2019, 70. [CrossRef]

54. Spooner, K.; Hong, T.; Nair, R.; Chow, N.C.C.; Broadhead, G.K.; Wijeyakumar, W.; Chang, A.A. Long-term outcomes of switching to aflibercept for treatment-resistant neovascular age-related macular degeneration. Acta Ophthalmol. 2019, 97, e706-e712. [CrossRef] [PubMed]

55. Muftuoglu, I.K.; Arcinue, C.A.; Tsai, F.F.; Alam, M.; Gaber, R.; Camacho, N.; You, Q.; Freeman, W.R. Long-Term Results of Pro Re Nata Regimen of Aflibercept Treatment in Persistent Neovascular Age-Related Macular Degeneration. Am. J. Ophthalmol. 2016, 167, 1-9. [CrossRef] [PubMed]

56. Cho, H.; Shah, C.P.; Weber, M.; Heier, J.S. Aflibercept for exudative AMD with persistent fluid on ranibizumab and/or bevacizumab. Br. J. Ophthalmol. 2013, 97, 1032-1035. [CrossRef] [PubMed]

57. Husum, Y.S.; Moe, M.C.; Bragadóttir, R.; Jørstad Ø, K. Switching to aflibercept versus continuing bevacizumab for treatmentresistant neovascular age-related macular degeneration: A one-year comparative observational study. Acta Ophthalmol. 2021. [CrossRef] [PubMed]

58. Hsia, N.Y.; Lin, C.J.; Lin, J.M.; Chen, W.L.; Tien, P.T.; Ho, Y.H.; Kuo, C.Y.; Tsai, Y.Y. Rescue effects of intravitreal aflibercept in the treatment of neovascular age-related macular degeneration. Taiwan J. Ophthalmol. 2015, 5, 128-131. [CrossRef] [PubMed]

59. Topal, T.; Kar, T.; Yıldırım, Y.; Sağdıç, S.K.; Büyükavşar, C.; Kaya, A.; Ayata, A.; Sönmez, M.; Ünal, M.H. Evaluation of Aflibercept Treatment Responses in Eyes with Bevacizumab/Ranibizumab-resistant Wet Age-related Macular Degeneration. Turk. J. Ophthalmol. 2017, 47, 133-137. [CrossRef]

60. Jørstad Ø, K.; Faber, R.T.; Moe, M.C. Two-year functional and anatomical results after converting treatment resistant eyes with exudative age-related macular degeneration to aflibercept in accordance with a treat and extend protocol. Acta Ophthalmol. 2017, 95, 460-463. [CrossRef]

61. Grewal, D.S.; Gill, M.K.; Sarezky, D.; Lyon, A.T.; Mirza, R.G. Visual and anatomical outcomes following intravitreal aflibercept in eyes with recalcitrant neovascular age-related macular degeneration: 12-month results. Eye 2014, 28, 895-899. [CrossRef]

62. Wykoff, C.C.; Brown, D.M.; Maldonado, M.E.; Croft, D.E. Aflibercept treatment for patients with exudative age-related macular degeneration who were incomplete responders to multiple ranibizumab injections (TURF trial). Br. J. Ophthalmol. 2014, 98, 951-955. [CrossRef]

63. Seguin-Greenstein, S.; Lightman, S.; Tomkins-Netzer, O. A Meta-Analysis of Studies Evaluating Visual and Anatomical Outcomes in Patients with Treatment Resistant Neovascular Age-Related Macular Degeneration following Switching to Treatment with Aflibercept. J. Ophthalmol. 2016, 2016, 4095852. [CrossRef] [PubMed]

64. Spooner, K.; Hong, T.; Wijeyakumar, W.; Chang, A.A. Switching to aflibercept among patients with treatment-resistant neovascular age-related macular degeneration: A systematic review with meta-analysis. Clin. Ophthalmol. 2017, 11, 161-177. [CrossRef]

65. Veritti, D.; Sarao, V.; Parravano, M.; Arias, L.; Varano, M.; Lanzetta, P. One-year results of aflibercept in vascularized pigment epithelium detachment due to neovascular AMD: A prospective study. Eur J. Ophthalmol. 2017, 27, 74-79. [CrossRef] [PubMed]

66. Rouvas, A.; Chatziralli, I.; Androu, A.; Mpougatsou, P.; Alonistiotis, D.; Douvali, M.; Kabanarou, S.A.; Theodossiadis, P. Ranibizumab versus aflibercept for the treatment of vascularized pigment epithelium detachment due to age-related macular degeneration. Int. Ophthalmol. 2019, 39, 431-440. [CrossRef] [PubMed]

67. Románek, J.; Palyzová, H.; Grygar, J.; Ernest, J. Aflibercept for Vascularised Serous Pigment Epithelial Detachment: One-Year Anatomical and Functional Results. Cesk Slov. Oftalmol. 2020, 76, 88-93. [CrossRef] [PubMed]

68. Kanesa-Thasan, A.; Grewal, D.S.; Gill, M.K.; Lyon, A.T.; Mirza, R.G. Quantification of Change in Pigment Epithelial Detachment Volume and Morphology After Transition to Intravitreal Aflibercept in Eyes With Recalcitrant Neovascular AMD: 18-Month Results. Ophthalmic Surg. Lasers Imaging Retina 2015, 46, 638-641. [CrossRef]

69. de Massougnes, S.; Dirani, A.; Ambresin, A.; Decugis, D.; Marchionno, L.; Mantel, I. Pigment Epithelial Detachment Response to Aflibercept in Neovascular Age-Related Macular Degeneration Refractory to Ranibizumab: Time Course and Drug Effects. Retina 2016, 36, 881-888. [CrossRef] [PubMed]

70. Kim, K.; Kim, E.S.; Kim, Y.; Yang, J.H.; Yu, S.Y.; Kwak, H.W. Outcome of intravitreal aflibercept for refractory pigment epithelial detachment with or without subretinal fluid and secondary to age-related macular degeneration. Retina 2019, 39, 303-313. [CrossRef] [PubMed] 
71. Clemens, C.R.; Alten, F.; Termühlen, J.; Mihailovic, N.; Rosenberger, F.; Heiduschka, P.; Eter, N. Prospective PED-study of intravitreal aflibercept for refractory vascularized pigment epithelium detachment due to age-related macular degeneration: Morphologic characteristics of non-responders in optical coherence tomography. Graefes Arch. Clin. Exp. Ophthalmol 2020, 258, 1411-1417. [CrossRef]

72. Lee, C.S.; Kim, A.J.; Baughman, D.; Egan, C.; Bailey, C.; Johnston, R.L.; Natha, S.; Khan, R.; Brand, C.; Akerele, T.; et al. Visual acuity improvement when switching from ranibizumab to aflibercept is not sustained. Retina 2018, 38, 951-956. [CrossRef]

73. Gale, R.P.; Pearce, I.; Eter, N.; Ghanchi, F.; Holz, F.G.; Schmitz-Valckenberg, S.; Balaskas, K.; Burton, B.J.L.; Downes, S.M.; Eleftheriadis, H.; et al. Anatomical and functional outcomes following switching from aflibercept to ranibizumab in neovascular age-related macular degeneration in Europe: SAFARI study. Br. J. Ophthalmol. 2020, 104, 493. [CrossRef] [PubMed]

74. Waibel, S.; Matthé, E.; Sandner, D. Results of Re-switch from Intravitreal Aflibercept to Ranibizumab in Patients with Exudative Age-related Macular Degeneration. Klin. Monbl. Augenheilkd 2018, 235, 616-621. [CrossRef] [PubMed]

75. Marquis, L.M.; Mantel, I. Beneficial switch from aflibercept to ranibizumab for the treatment of refractory neovascular age-related macular degeneration. Graefes Arch. Clin. Exp. Ophthalmol. 2020, 258, 1591-1596. [CrossRef] [PubMed]

76. Avaylon, J.; Lee, S.; Gallemore, R.P. Case Series on Initial Responses to Intravitreal Brolucizumab in Patients with Recalcitrant Chronic Wet Age-Related Macular Degeneration. Int. Med. Case Rep. J. 2020, 13, 145-152. [CrossRef] [PubMed]

77. Park, U.C.; Kim, B.H.; Choe, H.R.; Yeon, D.Y.; Yu, H.G. Long-term results of rescue photodynamic therapy for type 1 neovascularization refractory to anti-vascular endothelial growth factor. Acta Ophthalmol. 2020. [CrossRef] [PubMed]

78. Tozer, K.; Roller, A.B.; Chong, L.P.; Sadda, S.; Folk, J.C.; Mahajan, V.B.; Russell, S.R.; Boldt, H.C.; Sohn, E.H. Combination therapy for neovascular age-related macular degeneration refractory to anti-vascular endothelial growth factor agents. Ophthalmology 2013, 120, 2029-2034. [CrossRef] [PubMed]

79. Silva-Garcia, R.; McLellan, C.; Shaya, F.S.; Small, K.W. Long-lasting effects of anti-VEGF/photodynamic combination therapy in the treatment of exudative age-related macular degeneration: A retrospective chart review. Clin. Ophthalmol. 2014, 8, 2529-2532. [CrossRef] [PubMed]

80. Gallemore, R.P.; Wallsh, J.; Hudson, H.L.; Ho, A.C.; Chace, R.; Pearlman, J. Combination verteporfin photodynamic therapy ranibizumab-dexamethasone in choroidal neovascularization due to age-related macular degeneration: Results of a phase II randomized trial. Clin. Ophthalmol. 2017, 11, 223-231. [CrossRef]

81. Gallemore, R.; Nguyen, D. Review of Ophthalmology. When anti-VEGF treatment fails. 2008. Available online: https://www. reviewofophthalmology.com/article/when-anti-vegf-treatmentfails (accessed on 20 March 2021).

82. Tatar, O.; Yoeruek, E.; Szurman, P.; Bartz-Schmidt, K.U.; Adam, A.; Shinoda, K.; Eckardt, C.; Boeyden, V.; Claes, C.; Pertile, G.; et al. Effect of bevacizumab on inflammation and proliferation in human choroidal neovascularization. Arch. Ophthalmol. 2008, 126, 782-790. [CrossRef]

83. Tao, Y.; Jonas, J.B. Intravitreal bevacizumab combined with intravitreal triamcinolone for therapy-resistant exudative age-related macular degeneration. J. Ocul. Pharmacol. Ther. 2010, 26, 207-212. [CrossRef]

84. Todorich, B.; Thanos, A.; Yonekawa, Y.; Mane, G.; Hasbrook, M.; Thomas, B.J.; Woodward, M.A.; Williams, G.A.; Capone, A., Jr.; Wolfe, J.D.; et al. Simultaneous dexamethasone intravitreal implant and anti-VEGF therapy for neovascular age-related macular degeneration resistant to anti-VEGF monotherapy. J. Vitreoretin Dis. 2017, 1, 65-74. [CrossRef] [PubMed]

85. Barikian, A.; Salti, H.; Safar, A.; Mahfoud, Z.R.; Bashshur, Z.F. Intravitreal Dexamethasone Implant as Adjuvant Treatment for Bevacizumab- and Ranibizumab-Resistant Neovascular Age-Related Macular Degeneration: A Prospective Pilot Study. Retina 2017, 37, 1337-1344. [CrossRef] [PubMed]

86. Giancipoli, E.; Pinna, A.; Boscia, F.; Zasa, G.; Sotgiu, G.; Dore, S.; D’Amico Ricci, G. Intravitreal Dexamethasone in Patients with Wet Age-Related Macular Degeneration Resistant to Anti-VEGF: A Prospective Pilot Study. J. Ophthalmol. 2018, $2018,5612342$. [CrossRef] [PubMed]

87. Coscas, G.; Yamashiro, K.; Coscas, F.; De Benedetto, U.; Tsujikawa, A.; Miyake, M.; Gemmy Cheung, C.M.; Wong, T.Y.; Yoshimura, N. Comparison of Exudative Age-related Macular Degeneration Subtypes in Japanese and French Patients: Multicenter Diagnosis With Multimodal Imaging. Am. J. Ophthalmol. 2014, 158, 309-318.e302. [CrossRef]

88. Wong, C.W.; Wong, T.Y.; Cheung, C.M.G. Polypoidal Choroidal Vasculopathy in Asians. J. Clin. Med. 2015, 4, 782-821. [CrossRef]

89. Koh, A.; Lee, W.K.; Chen, L.J.; Chen, S.J.; Hashad, Y.; Kim, H.; Lai, T.Y.; Pilz, S.; Ruamviboonsuk, P.; Tokaji, E.; et al. EVEREST study: Efficacy and safety of verteporfin photodynamic therapy in combination with ranibizumab or alone versus ranibizumab monotherapy in patients with symptomatic macular polypoidal choroidal vasculopathy. Retina 2012, 32, 1453-1464. [CrossRef] [PubMed]

90. Kokame, G.T.; Yeung, L.; Teramoto, K.; Lai, J.C.; Wee, R. Polypoidal Choroidal Vasculopathy Exudation and Hemorrhage: Results of Monthly Ranibizumab Therapy at One Year. Ophthalmologica 2014, 231, 94-102. [CrossRef] [PubMed]

91. Wong, C.W.; Cheung, C.M.; Mathur, R.; Li, X.; Chan, C.M.; Yeo, I.; Wong, E.; Lee, S.Y.; Wong, D.; Wong, T.Y. Three-Year Results of Polypoidal Choroidal Vasculopathy Treated with Photodynamic Therapy: Retrospective Study and Systematic Review. Retina 2015, 35, 1577-1593. [CrossRef]

92. Yamashita, A.; Shiraga, F.; Shiragami, C.; Ono, A.; Tenkumo, K. One-year results of reduced-fluence photodynamic therapy for polypoidal choroidal vasculopathy. Am. J. Ophthalmol. 2010, 149, 465-471.e461. [CrossRef] [PubMed] 
93. Lim, T.H.; Lai, T.Y.Y.; Takahashi, K.; Wong, T.Y.; Chen, L.J.; Ruamviboonsuk, P.; Tan, C.S.; Lee, W.K.; Cheung, C.M.G.; Ngah, N.F.; et al. Comparison of Ranibizumab With or Without Verteporfin Photodynamic Therapy for Polypoidal Choroidal Vasculopathy: The EVEREST II Randomized Clinical Trial. JAMA Ophthalmol. 2020, 138, 935-942. [CrossRef] [PubMed]

94. Kokame, G.T.; deCarlo, T.E.; Kaneko, K.N.; Omizo, J.N.; Lian, R. Anti-Vascular Endothelial Growth Factor Resistance in Exudative Macular Degeneration and Polypoidal Choroidal Vasculopathy. Ophthalmol. Retina 2019, 3, 744-752. [CrossRef]

95. Kokame, G.T.; Liu, K.; Kokame, K.A.; Kaneko, K.N.; Omizo, J.N. Clinical Characteristics of Polypoidal Choroidal Vasculopathy and Anti-Vascular Endothelial Growth Factor Treatment Response in Caucasians. Ophthalmologica 2020, 243, 178-186. [CrossRef]

96. Lee, J.H.; Lee, S.C.; Byeon, S.H.; Koh, H.J.; Kim, S.S.; Lee, C.S. Efficacy of Adjuvant Topical Dorzolamide-Timolol in Patients with Neovascular Age-Related Macular Degeneration Refractory to Anti-Vascular Endothelial Growth Factor Therapy. Retina 2019, 39, 1953-1958. [CrossRef] [PubMed]

97. Li, S.; Hu, A.; Wang, W.; Ding, X.; Lu, L. Combinatorial treatment with topical NSAIDs and anti-VEGF for age-related macular degeneration, a meta-analysis. PLoS ONE 2017, 12, e0184998. [CrossRef]

98. Zur, D.; Loewenstein, A.; Barak, A. One-year results from clinical practice of epimacular strontium-90 brachytherapy for the treatment of subfoveal choroidal neovascularization secondary to AMD. Ophthalmic Surg. Lasers Imaging Retina 2015, 46, 338-343. [CrossRef] [PubMed]

99. Zhao, M.; Mantel, I.; Gelize, E.; Li, X.; Xie, X.; Arboleda, A.; Seminel, M.; Levy-Boukris, R.; Dernigoghossian, M.; Prunotto, A.; et al. Mineralocorticoid receptor antagonism limits experimental choroidal neovascularization and structural changes associated with neovascular age-related macular degeneration. Nat. Commun. 2019, 10, 369. [CrossRef] [PubMed]

100. Peyman, G.; Tsipursky, M.; Gohel, P.; Conway, M. Regression of peripapillary choroidal neovascularization after oscillatory transpupillary thermotherapy and anti-VEGF pharmacotherapy. Eur. J. Ophthalmol. 2011, 21, 162-172. [CrossRef] [PubMed]

101. Shah, S.U.; Haller, J.A. Vitreomacular traction in a case of exudative age-related macular degeneration resistant to anti-VEGF therapy. Acta Ophthalmol. 2012, 90, e569-e570. [CrossRef] [PubMed]

102. Kimura, S.; Morizane, Y.; Toshima, S.; Hosogi, M.; Kumase, F.; Hosokawa, M.; Shiode, Y.; Fujiwara, A.; Shiraga, F. Efficacy of vitrectomy and inner limiting membrane peeling in age-related macular degeneration resistant to anti-vascular endothelial growth factor therapy, with vitreomacular traction or epiretinal membrane. Graefes Arch. Clin. Exp. Ophthalmol 2016, 254, 1731-1736. [CrossRef] [PubMed]

103. Zhu, L.; Parker, M.; Enemchukwu, N.; Shen, M.; Zhang, G.; Yan, Q.; Handa, J.T.; Fang, L.; Fu, Y. Combination of apolipoprotein-AI/apolipoprotein-A-I binding protein and anti-VEGF treatment overcomes anti-VEGF resistance in choroidal neovascularization in mice. Commun. Biol. 2020, 3, 386. [CrossRef] [PubMed]

104. Martidis, A.; Duker, J.S.; Greenberg, P.B.; Rogers, A.H.; Puliafito, C.A.; Reichel, E.; Baumal, C. Intravitreal triamcinolone for refractory diabetic macular edema. Ophthalmology 2002, 109, 920-927. [CrossRef]

105. Jonas, J.B.; Kreissig, I.; Söfker, A.; Degenring, R.F. Intravitreal injection of triamcinolone for diffuse diabetic macular edema. Arch. Ophthalmol. 2003, 121, 57-61. [CrossRef] [PubMed]

106. Massin, P.; Audren, F.; Haouchine, B.; Erginay, A.; Bergmann, J.F.; Benosman, R.; Caulin, C.; Gaudric, A. Intravitreal triamcinolone acetonide for diabetic diffuse macular edema: Preliminary results of a prospective controlled trial. Ophthalmology 2004, 111, 218-224, discussion 224-215. [CrossRef] [PubMed]

107. Kim, J.H.; Lee, T.G.; Lew, Y.J. Short-term efficacy of intravitreal triamcinolone acetonide for bevacizumab-resistant diabetic macular oedema. Acta Ophthalmol. 2015, 93, e178-e179. [CrossRef] [PubMed]

108. Jeon, S.; Lee, W.K. Effect of intravitreal triamcinolone in diabetic macular edema unresponsive to intravitreal bevacizumab. Retina 2014, 34, 1606-1611. [CrossRef] [PubMed]

109. Kocabora, M.S.; Yilmazli, C.; Taskapili, M.; Gulkilik, G.; Durmaz, S. Development of ocular hypertension and persistent glaucoma after intravitreal injection of triamcinolone. Clin. Ophthalmol. 2008, 2, 167-171. [CrossRef] [PubMed]

110. Çekiç, O.; Chang, S.; Tseng, J.J.; Akar, Y.; Barile, G.R.; Schiff, W.M. Cataract Progression After Intravitreal Triamcinolone Injection. Am. J. Ophthalmol. 2005, 139, 993-998. [CrossRef] [PubMed]

111. Nalçacı, S.; Akkın, C.; Afrashi, F. Dexamethasone Implant in Patients with Diabetic Macular Edema Resistant to Anti-VEGF Therapy. Turk. J. Ophthalmol. 2019, 49, 73-77. [CrossRef] [PubMed]

112. Totan, Y.; Güler, E.; Gürağaç, F.B. Dexamethasone Intravitreal Implant for Chronic Diabetic Macular Edema Resistant to Intravitreal Bevacizumab Treatment. Curr Eye Res. 2016, 41, 107-113. [CrossRef] [PubMed]

113. Shah, A.R.; Xi, M.; Abbey, A.M.; Yonekawa, Y.; Faia, L.J.; Hassan, T.S.; Ruby, A.J.; Wolfe, J.D. Short-term Efficacy of Intravitreal Dexamethasone Implant in Vitrectomized Eyes with Recalcitrant Diabetic Macular Edema and Prior Anti-VEGF Therapy. J. Ophthalmic Vis. Res. 2016, 11, 183-187. [CrossRef]

114. Rishi, P.; Rishi, E.; Kuniyal, L.; Mathur, G. Short-term results of intravitreal dexamethasone implant (OZURDEX(®)) in treatment of recalcitrant diabetic macular edema: A case series. Oman. J. Ophthalmol. 2012, 5, 79-82. [CrossRef] [PubMed]

115. Güler, E.; Totan, Y.; Betül Güragaç, F. Intravitreal bevacizumab and dexamethasone implant for treatment of chronic diabetic macular edema. Cutan. Ocul. Toxicol. 2017, 36, 180-184. [CrossRef] [PubMed]

116. Rishi, P.; Rishi, E.; Attiku, Y.; Dhami, A.; Iyer, V. Real-world experience with pro re nata dosing of intravitreal dexamethasone implant for eyes with refractory diabetic macular edema. GMS Ophthalmol. Cases 2020, 10. [CrossRef] 
117. Hatz, K.; Ebneter, A.; Tuerksever, C.; Pruente, C.; Zinkernagel, M. Repeated Dexamethasone Intravitreal Implant for the Treatment of Diabetic Macular Oedema Unresponsive to Anti-VEGF Therapy: Outcome and Predictive SD-OCT Features. Ophthalmologica 2018, 239, 205-214. [CrossRef] [PubMed]

118. Iacono, P.; Parodi, M.B.; Scaramuzzi, M.; Bandello, F. Morphological and functional changes in recalcitrant diabetic macular oedema after intravitreal dexamethasone implant. Br. J. Ophthalmol. 2017, 101, 791-795. [CrossRef] [PubMed]

119. Busch, C.; Fraser-Bell, S.; Iglicki, M.; Lupidi, M.; Couturier, A.; Chaikitmongkol, V.; Giancipoli, E.; Rodríguez-Valdés, P.J.; Gabrielle, P.H.; Laíns, I.; et al. Real-world outcomes of non-responding diabetic macular edema treated with continued anti-VEGF therapy versus early switch to dexamethasone implant: 2-year results. Acta Diabetol. 2019, 56, 1341-1350. [CrossRef]

120. Maturi, R.K.; Glassman, A.R.; Liu, D.; Beck, R.W.; Bhavsar, A.R.; Bressler, N.M.; Jampol, L.M.; Melia, M.; Punjabi, O.S.; Salehi-Had, H.; et al. Effect of Adding Dexamethasone to Continued Ranibizumab Treatment in Patients With Persistent Diabetic Macular Edema: A DRCR Network Phase 2 Randomized Clinical Trial. JAMA Ophthalmol. 2018, 136, 29-38. [CrossRef]

121. Khan, Z.; Kuriakose, R.K.; Khan, M.; Chin, E.K.; Almeida, D.R. Efficacy of the Intravitreal Sustained-Release Dexamethasone Implant for Diabetic Macular Edema Refractory to Anti-Vascular Endothelial Growth Factor Therapy: Meta-Analysis and Clinical Implications. Ophthalmic Surg. Lasers Imaging Retina 2017, 48, 160-166. [CrossRef] [PubMed]

122. Coney, J.M. Fluocinolone acetonide $0.19 \mathrm{mg}$ intravitreal implant improves foveal thickness and reduces treatment burden for up to 1 year in eyes with persistent diabetic macular edema. Int. Med. Case Rep. J. 2019, 12, 161-169. [CrossRef]

123. McCluskey, J.D.; Kaufman, P.L.; Wynne, K.; Lewis, G. Early adoption of the fluocinolone acetonide (FAc) intravitreal implant in patients with persistent or recurrent diabetic macular edema (DME). Int. Med. Case Rep. J. 2019, 12, 93-102. [CrossRef]

124. Schmit-Eilenberger, V.K. A novel intravitreal fluocinolone acetonide implant (Iluvien(®)) in the treatment of patients with chronic diabetic macular edema that is insufficiently responsive to other medical treatment options: A case series. Clin. Ophthalmol. 2015, 9, 801-811. [CrossRef]

125. Massin, P.; Erginay, A.; Dupas, B.; Couturier, A.; Tadayoni, R. Efficacy and safety of sustained-delivery fluocinolone acetonide intravitreal implant in patients with chronic diabetic macular edema insufficiently responsive to available therapies: A real-life study. Clin. Ophthalmol. 2016, 10, 1257-1264. [CrossRef] [PubMed]

126. La Mantia, A.; Hawrami, A.; Laviers, H.; Patra, S.; Zambarakji, H. Treatment of refractory diabetic macular edema with a fluocinolone acetonide implant in vitrectomized and non-vitrectomized eyes. Int. J. Ophthalmol. 2018, 11, 1951-1956. [CrossRef] [PubMed]

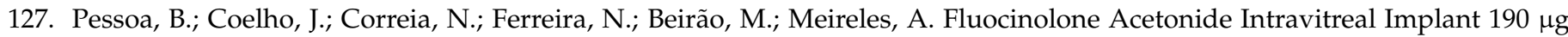
(ILUVIEN@) in Vitrectomized versus Nonvitrectomized Eyes for the Treatment of Chronic Diabetic Macular Edema. Ophthalmic Res. 2018, 59, 68-75. [CrossRef] [PubMed]

128. Chronopoulos, A.; Chronopoulos, P.; Ashurov, A.; Korb, C.; Pfeiffer, N.; Hattenbach, L.O. Switching to intravitreal fluocinolone acetonide implant for refractory diabetic macular edema: 12- and 24-month results. Eur. J. Ophthalmol. 2021. [CrossRef] [PubMed]

129. Entezari, M.; Ahmadieh, H.; Dehghan, M.H.; Ramezani, A.; Bassirnia, N.; Anissian, A. Posterior sub-tenon triamcinolone for refractory diabetic macular edema: A randomized clinical trial. Eur. J. Ophthalmol. 2005, 15, 746-750. [CrossRef]

130. Bakri, S.J.; Kaiser, P.K. Posterior subtenon triamcinolone acetonide for refractory diabetic macular edema. Am. J. Ophthalmol. 2005, 139, 290-294. [CrossRef] [PubMed]

131. Eriş, E.; Perente, I.; Vural, E.; Vural, A.; Seymen, Z.; Celebi, A.R.C.; Erdogan, G.; Ozkaya, A.; Artunay, O. Evaluation of the effect of combined intravitreal ranibizumab injection and sub-tenon steroid injection in the treatment of resistant diabetic macular edema. Int. Ophthalmol. 2019, 39, 1575-1580. [CrossRef] [PubMed]

132. Choi, Y.J.; Oh, I.K.; Oh, J.R.; Huh, K. Intravitreal versus posterior subtenon injection of triamcinolone acetonide for diabetic macular edema. Korean J. Ophthalmol. 2006, 20, 205-209. [CrossRef] [PubMed]

133. Sanders, S.M.; Mendiola, L.L.; Hatcher, J.; Taba, K. A Comparison of IOP Rise and Associated Risk Factors After Sub-Tenon's Triamcinolone Injection versus Intravitreal Triamcinolone Injection in the Treatment of Macular Edema. Investig. Ophthalmol. Vis. Sci. 2009, 50, 1479.

134. Sivaprasad, S.; Prevost, A.T.; Vasconcelos, J.C.; Riddell, A.; Murphy, C.; Kelly, J.; Bainbridge, J.; Tudor-Edwards, R.; Hopkins, D.; Hykin, P. Clinical efficacy of intravitreal aflibercept versus panretinal photocoagulation for best corrected visual acuity in patients with proliferative diabetic retinopathy at 52 weeks (CLARITY): A multicentre, single-blinded, randomised, controlled, phase $2 \mathrm{~b}$, non-inferiority trial. Lancet 2017, 389, 2193-2203. [CrossRef] [PubMed]

135. Obeid, A.; Su, D.; Patel, S.N.; Uhr, J.H.; Borkar, D.; Gao, X.; Fineman, M.S.; Regillo, C.D.; Maguire, J.I.; Garg, S.J.; et al. Outcomes of Eyes Lost to Follow-up with Proliferative Diabetic Retinopathy That Received Panretinal Photocoagulation versus Intravitreal Anti-Vascular Endothelial Growth Factor. Ophthalmology 2019, 126, 407-413. [CrossRef] [PubMed]

136. Photocoagulation for Diabetic Macular Edema. Early Treatment Diabetic Retinopathy Study report number 1. Early Treatment Diabetic Retinopathy Study research group. Arch. Ophthalmol. 1985, 103, 1796-1806. [CrossRef]

137. Neubauer, A.S.; Langer, J.; Liegl, R.; Haritoglou, C.; Wolf, A.; Kozak, I.; Seidensticker, F.; Ulbig, M.; Freeman, W.R.; Kampik, A.; et al. Navigated macular laser decreases retreatment rate for diabetic macular edema: A comparison with conventional macular laser. Clin. Ophthalmol. 2013, 7, 121-128. [CrossRef]

138. Blindbaek, S.L.; Peto, T.; Grauslund, J. Aflibercept and navigated versus conventional laser in diabetic macular oedema: A 12-month randomized clinical trial. Acta Ophthalmol. 2020, 98, 347-352. [CrossRef] [PubMed] 
139. Mitchell, P.; Bandello, F.; Schmidt-Erfurth, U.; Lang, G.E.; Massin, P.; Schlingemann, R.O.; Sutter, F.; Simader, C.; Burian, G.; Gerstner, O.; et al. The RESTORE study: Ranibizumab monotherapy or combined with laser versus laser monotherapy for diabetic macular edema. Ophthalmology 2011, 118, 615-625. [CrossRef]

140. Ishibashi, T.; Li, X.; Koh, A.; Lai, T.Y.; Lee, F.L.; Lee, W.K.; Ma, Z.; Ohji, M.; Tan, N.; Cha, S.B.; et al. The REVEAL Study: Ranibizumab Monotherapy or Combined with Laser versus Laser Monotherapy in Asian Patients with Diabetic Macular Edema. Ophthalmology 2015, 122, 1402-1415. [CrossRef]

141. Moisseiev, E.; Abbassi, S.; Thinda, S.; Yoon, J.; Yiu, G.; Morse, L.S. Subthreshold micropulse laser reduces anti-VEGF injection burden in patients with diabetic macular edema. Eur J. Ophthalmol. 2018, 28, 68-73. [CrossRef] [PubMed]

142. Abouhussein, M.A.; Gomaa, A.R. Aflibercept plus micropulse laser versus aflibercept monotherapy for diabetic macular edema: 1-year results of a randomized clinical trial. Int. Ophthalmol. 2020, 40, 1147-1154. [CrossRef] [PubMed]

143. Akhlaghi, M.; Dehghani, A.; Pourmohammadi, R.; Asadpour, L.; Pourazizi, M. Effects of subthreshold diode micropulse laser photocoagulation on treating patients with refractory diabetic macular edema. J. Curr. Ophthalmol. 2019, 31, 157-160. [CrossRef] [PubMed]

144. Klein, K.A.; Cleary, T.S.; Reichel, E. Effect of intravitreal aflibercept on recalcitrant diabetic macular edema. Int. J. Retina Vitr. 2017, 3, 16. [CrossRef] [PubMed]

145. Salimi, A.; Vila, N.; Modabber, M.; Kapusta, M. One-year outcomes of Aflibercept for refractory diabetic macular edema in Bevacizumab nonresponders. Indian J. Ophthalmol. 2021, 69, 360-367. [CrossRef] [PubMed]

146. Laiginhas, R.; Silva, M.I.; Rosas, V.; Penas, S.; Fernandes, V.A.; Rocha-Sousa, A.; Carneiro, Â.; Falcão-Reis, F.; Falcão, M.S. Aflibercept in diabetic macular edema refractory to previous bevacizumab: Outcomes and predictors of success. Graefes Arch. Clin. Exp. Ophthalmol. 2018, 256, 83-89. [CrossRef]

147. Mirshahi, A.; Tadayoni, R.; Mohsenzadeh, N.; Saeidi Rezvani, T.; Abrishami, M. Efficacy of adjuvant topical timolol-dorzolamide with intravitreal bevacizumab injection in diabetic macular edema: A contralateral eye study. J. Curr. Ophthalmol. 2019, 31, 168-171. [CrossRef] [PubMed]

148. Genead, M.A.; Fishman, G.A. Efficacy of sustained topical dorzolamide therapy for cystic macular lesions in patients with retinitis pigmentosa and usher syndrome. Arch. Ophthalmol. 2010, 128, 1146-1150. [CrossRef]

149. Huang, Q.; Chen, R.; Lin, X.; Xiang, Z. Efficacy of carbonic anhydrase inhibitors in management of cystoid macular edema in retinitis pigmentosa: A meta-analysis. PLoS ONE 2017, 12, e0186180. [CrossRef]

150. Terashima, H.; Suzuki, K.; Kato, K.; Sugai, N. Membrane-bound carbonic anhydrase activity in the rat corneal endothelium and retina. Jpn J. Ophthalmol. 1996, 40, 142-153.

151. Lavine, J.A.; Farnoodian, M.; Wang, S.; Darjatmoko, S.R.; Wright, L.S.; Gamm, D.M.; Ip, M.S.; Sorenson, C.M.; Sheibani, N. $\beta 2$-Adrenergic Receptor Antagonism Attenuates CNV Through Inhibition of VEGF and IL-6 Expression. Invest. Ophthalmol. Vis. Sci. 2017, 58, 299-308. [CrossRef]

152. Asahi, M.G.; Bobarnac Dogaru, G.L.; Onishi, S.M.; Gallemore, R.P. Strong topical steroid, NSAID, and carbonic anhydrase inhibitor cocktail for treatment of cystoid macular edema. Int. Med Case Rep. J. 2015, 8, 305-312. [CrossRef]

153. Pinna, A.; Blasetti, F.; Ricci, G.D.; Boscia, F. Bromfenac eyedrops in the treatment of diabetic macular edema: A pilot study. Eur. J. Ophthalmol. 2017, 27, 326-330. [CrossRef]

154. Soheilian, M.; Karimi, S.; Ramezani, A.; Montahai, T.; Yaseri, M.; Soheilian, R.; Peyman, G.A. Intravitreal diclofenac versus intravitreal bevacizumab in naive diabetic macular edema: A randomized double-masked clinical trial. Int. Ophthalmol. 2015, 35, 421-428. [CrossRef]

155. Faghihi, H.; Yahyapour, H.; Mahmoudzadeh, R.; Faghihi, S. Comparison of Intravitreal Bevacizumab and Intravitreal Diclofenac in the Treatment of Diabetic Macular Edema: A 6-month Follow-up. Med. Hypothesis Discov. Innov. Ophthalmol. 2017, 6, 67-75. [PubMed]

156. Ghanbari, H.; Kianersi, F.; Sonbolestan, S.A.; Abtahi, M.A.; Akbari, M.; Abtahi, Z.A.; Abtahi, S.H. Intravitreal Diclofenac plus Bevacizumab versus Bevacizumab alone in treatment-naive diabetic macular edema: A randomized double-blind clinical trial. Int. Ophthalmol. 2017, 37, 867-874. [CrossRef] [PubMed]

157. Frenkel, S.; Hendler, K.; Siegal, T.; Shalom, E.; Pe'er, J. Intravitreal methotrexate for treating vitreoretinal lymphoma: 10 years of experience. Br. J. Ophthalmol. 2008, 92, 383-388. [CrossRef] [PubMed]

158. Benner, J.D.; Dao, D.; Butler, J.W.; Hamill, K.I. Intravitreal methotrexate for the treatment of proliferative vitreoretinopathy. BMJ Open Ophthalmol. 2019, 4, e000293. [CrossRef] [PubMed]

159. Galor, A.; Karp, C.L.; Chhabra, S.; Barnes, S.; Alfonso, E.C. Topical interferon alpha $2 b$ eye-drops for treatment of ocular surface squamous neoplasia: A dose comparison study. Br. J. Ophthalmol. 2010, 94, 551. [CrossRef] [PubMed]

160. Yin, M.; Li, H.; Zhang, Y.; Dai, H.; Luo, F.; Pan, Z. Interferon Alpha-2b Eye Drops Prevent Recurrence of Pterygium After the Bare Sclera Technique: A Single-Center, Sequential, and Controlled Study. Cornea 2019, 38, 1239. [CrossRef]

161. Falavarjani, K.G.; Golabi, S.; Modarres, M. Intravitreal injection of methotrexate in persistent diabetic macular edema: A 6-month follow-up study. Graefes Arch. Clin. Exp. Ophthalmol. 2016, 254, 2159-2164. [CrossRef] [PubMed]

162. Maleki, A.; Stephenson, A.P.; Hajizadeh, F. Topical Interferon Alpha 2b in the Treatment of Refractory Diabetic Macular Edema. J. Ophthalmic Vis. Res. 2020, 15, 453-458. [CrossRef]

163. Ip, M.S.; Scott, I.U.; VanVeldhuisen, P.C.; Oden, N.L.; Blodi, B.A.; Fisher, M.; Singerman, L.J.; Tolentino, M.; Chan, C.K.; Gonzalez, V.H. A randomized trial comparing the efficacy and safety of intravitreal triamcinolone with observation to treat vision loss 
associated with macular edema secondary to central retinal vein occlusion: The Standard Care vs Corticosteroid for Retinal Vein Occlusion (SCORE) study report 5. Arch. Ophthalmol. 2009, 127, 1101-1114. [CrossRef]

164. Scott, I.U.; Ip, M.S.; VanVeldhuisen, P.C.; Oden, N.L.; Blodi, B.A.; Fisher, M.; Chan, C.K.; Gonzalez, V.H.; Singerman, L.J.; Tolentino, M.; et al. A randomized trial comparing the efficacy and safety of intravitreal triamcinolone with standard care to treat vision loss associated with macular Edema secondary to branch retinal vein occlusion: The Standard Care vs Corticosteroid for Retinal Vein Occlusion (SCORE) study report 6. Arch. Ophthalmol. 2009, 127, 1115-1128. [CrossRef] [PubMed]

165. Yong, M.H.; Amin, A.; Mushawiahti, M.; Bastion, M.L. Recalcitrant cystoid macular oedema in an eye with ischaemic central retinal vein occlusion-What's next? Med. J. Malays. 2015, 70, 358-360.

166. Ip, M.S.; Oden, N.L.; Scott, I.U.; VanVeldhuisen, P.C.; Blodi, B.A.; Ghuman, T.; Baker, C.W. Month 12 Outcomes After Treatment Change at Month 6 Among Poor Responders to Aflibercept or Bevacizumab in Eyes With Macular Edema Secondary to Central or Hemiretinal Vein Occlusion: A Secondary Analysis of the SCORE2 Study. JAMA Ophthalmol. 2019, 137, 281-287. [CrossRef]

167. Georgalas, L.; Tservakis, I.; Kiskira, E.E.; Petrou, P.; Papaconstantinou, D.; Kanakis, M. Efficacy and safety of dexamethasone intravitreal implant in patients with retinal vein occlusion resistant to anti-VEGF therapy: A 12-month prospective study. Cutan. Ocul. Toxicol. 2019, 38, 330-337. [CrossRef] [PubMed]

168. Wolfe, J.D.; Shah, A.R.; Yonekawa, Y.; Al Faran, A.; Franklin, M.S.; Abbey, A.M.; Capone, A., Jr. Receiver operating characteristic curve to predict anti-VEGF resistance in retinal vein occlusions and efficacy of Ozurdex. Eur. J. Ophthalmol. 2016, 26, 168-173. [CrossRef]

169. Wallsh, J.; Sharareh, B.; Gallemore, R. Therapeutic effect of dexamethasone implant in retinal vein occlusions resistant to anti-VEGF therapy. Clin. Ophthalmol. 2016, 10, 947-954. [CrossRef]

170. Campochiaro, P.A.; Marcus, D.M.; Awh, C.C.; Regillo, C.; Adamis, A.P.; Bantseev, V.; Chiang, Y.; Ehrlich, J.S.; Erickson, S.; Hanley, W.D.; et al. The Port Delivery System with Ranibizumab for Neovascular Age-Related Macular Degeneration: Results from the Randomized Phase 2 Ladder Clinical Trial. Ophthalmology 2019, 126, 1141-1154. [CrossRef] [PubMed]

171. Khanani, A.M.; Callanan, D.; Dreyer, R.; Chen, S.; Howard, J.G.; Hopkins, J.J.; Lin, C.Y.; Lorenz-Candlin, M.; Makadia, S.; Patel, S.; et al. End-of-Study Results for the Ladder Phase 2 Trial of the Port Delivery System with Ranibizumab for Neovascular Age-Related Macular Degeneration. Ophthalmol. Retina 2020. [CrossRef]

172. Khanani, A.M.; Patel, S.S.; Ferrone, P.J.; Osborne, A.; Sahni, J.; Grzeschik, S.; Basu, K.; Ehrlich, J.S.; Haskova, Z.; Dugel, P.U. Efficacy of Every Four Monthly and Quarterly Dosing of Faricimab vs Ranibizumab in Neovascular Age-Related Macular Degeneration: The STAIRWAY Phase 2 Randomized Clinical Trial. JAMA Ophthalmol. 2020, 138, 964-972. [CrossRef] [PubMed]

173. Sahni, J.; Dugel, P.U.; Patel, S.S.; Chittum, M.E.; Berger, B.; Del Valle Rubido, M.; Sadikhov, S.; Szczesny, P.; Schwab, D.; Nogoceke, E.; et al. Safety and Efficacy of Different Doses and Regimens of Faricimab vs Ranibizumab in Neovascular Age-Related Macular Degeneration: The AVENUE Phase 2 Randomized Clinical Trial. JAMA Ophthalmol. 2020, 138, 955-963. [CrossRef] [PubMed]

174. Alkahest. Alkahest Presents Positive Results from Phase 2a Open Label Study of AKST4290 in Treatment-Naïve Neovascular AMD at Retina World Congress. 2019. Available online: https://www.biospace.com/article/releases/alkahest-presents-positiveresults-from-phase-2a-open-label-study-of-akst4290-in-treatment-naive-neovascular-amd-at-retina-world-congress / (accessed on 23 April 2021).

175. Kaiser, P.K. Emerging therapies for neovascular age-related macular degeneration: Drugs in the pipeline. Ophthalmology 2013, 120, S11-S15. [CrossRef] [PubMed] 